\title{
Good things come in threes: triplet flow in recent hip-hop music
}

\section{Introduction}

In 2016, Sony Pictures produced The Get Down, a Netflix-released musical drama series chronicling the emergence of hip-hop culture in late 1970s South Bronx, New York. Early on in the series, the teenage protagonists form a (fictitious) hip-hop group called the Get Down Brothers. ${ }^{1}$ In various episodes, the Get Down Brothers give live performances; most viewers familiar with early hip-hop music would agree that the music used in The Get Down is stylistically consistent with the actual hip-hop music produced in the Bronx at that time. But during the sixth episode of the series, while engaging in a rap battle with a rival group, the Get Down Brothers collectively break into a rap sequence built on triplet rhythms, transcribed in Example 1. In presenting this scene, the show departs from the musical-stylistic norms of the period it portrays. Rapping in triplets - what I henceforth call triplet flow - was virtually unheard of at this time; the earliest recorded examples appear nearly a decade later. ${ }^{2}$ Furthermore, triplet flow's origins exhibit closer ties to hip-hop music from other American regions, such as the South and Midwest- but not New York. ${ }^{3}$ I do not wish to admonish The Get Down for its apparent anachronisms, but rather to ask the question: what motivated the shows' creators to include a relatively modern rapping technique in this scene?

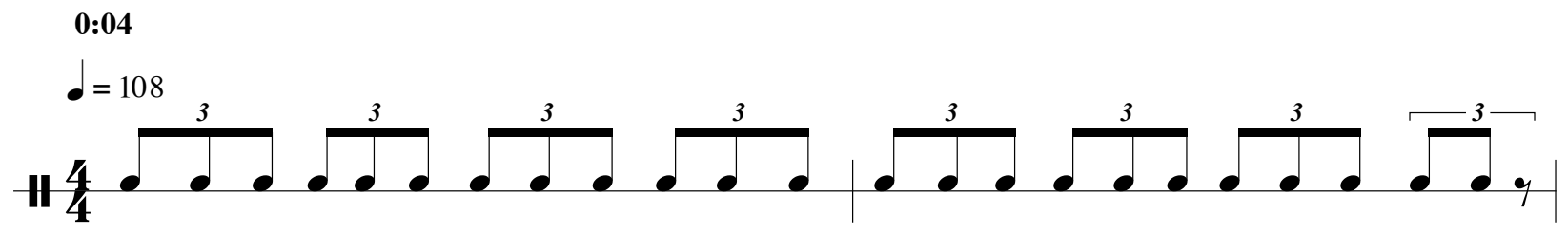

Shao-lin's the D-J that we call con-duc-tor 'cause Shao-lin Fan-tas-tic's a bad mo-ther (fuck-er!)

Example 1: 'Get Down Brothers vs. Notorious 3' (The Get Down, Netflix, 2016). This excerpt comes from the final episode of series one, which is set in 1977. The time stamp references the song as it appears on The Get Down soundtrack.

For those familiar with commercial hip-hop music since approximately 2012, the answer to this question might seem obvious. By featuring triplet flow in its music, The Get Down bears witness to this flow style's popularity in recent hip-hop music. Such popularity can perhaps be best seen through the critical and commercial success of Cardi B's debut album, Invasion of

\footnotetext{
${ }^{1}$ While some hip-hop artists that appear as characters in the show are drawn from real life (such as Grandmaster Flash and DJ Kool Herc), others are fictitious (such as Shaolin Fantastic and the Get Down Brothers).

${ }^{2}$ Adam Krims $(2000,15)$ describes flow as 'an MCs rhythmic delivery' of lyrics, while Kyle Adams (2009) expands this definition to include a consideration of accent, phrasing, articulation, and other musical elements. Triplet flow appears to be the preferred term for the practice of rapping in triplets, as used in Caswell, 2017. Most of the earliest commercially recorded hip-hop flow involved duple- and quadruple-based vocal rhythms, and not triplets. Rapped triplets do briefly appear in some later releases, such as 'Roxanne Roxanne' (UTFO, 1984), and 'Roxanne's Revenge' (Roxanne Shanté, 1984), but they generally appear to be uncommon during the 1980s.

${ }^{3}$ Cleveland-based Bone Thugs-n-Harmony and Memphis-based Three 6 Mafia both use triplet flow extensively through the 1990s. For examples, see E. 1999 Eternal (Bone Thugs-n-Harmony, 1995) and Mystic Stylez (Three 6 Mafia, 1995).
}

This is an accepted manuscript. Please cite as:

Duinker, Ben. 2019. "Good Things Come in Threes: Triplet Flow in Recent Hip-Hop Music." Popular Music 38 (3): 423-456. 
Privacy (2018), on which the lead single (among others) 'Bodak Yellow' features passages of triplet flow (see Example 2). ${ }^{4}$

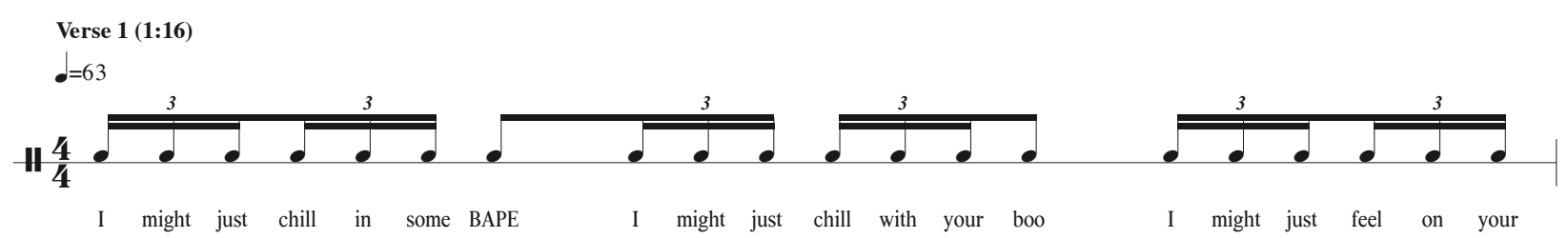

Example 2: 'Bodak Yellow' (Cardi B., 2018).

This popularity inspires the present study, wherein I consider the practice of triplet flow in several ways. First, based on the examples discussed in this paper, I formalize a definition of triplet flow, enumerating several types, and situating these in relation to the taxonomy of flow proposed by hip-hop scholar Adam Krims (2000). Second, I survey some early examples of triplet flow by artists such as Public Enemy, Freestyle Fellowship, Bone Thugs-n-Harmony, and Three 6 Mafia, with the aim of showing how some stylistic traits of these early examples have permeated the types of triplet flow that are currently widely used. I posit that a general downward trend of song tempos in recent years provides the most significant stylistic condition that enables triplet flow's current prevalence. Third, I present and analyse a corpus of fifty songs released since 2012 that feature triplet flow, identifying some general stylistic traits common to these songs. I illustrate these traits by discussing songs by G-Eazy, Kendrick Lamar, Young Thug, Run the Jewels, and Big Sean. I also briefly survey several songs that mix triplet flow with duple rhythms, examining the phenomenological effects this mixture produces, particularly with regard to the pacing of motional energy (a term I borrow from Matthew Butterfield's work on rhythm). ${ }^{5}$ Finally, I analyse two songs in greater detail: 'Dark Sky (Skyscrapers)' by Big Sean (2015) and 'Panda' by Desiigner (2015) feature lengthy passages of triplet flow and afford the opportunity for a discussion of how it facilitates creativity, rhetoric, and diversity in an MC's flow. Through this work I contend that triplet flow represents one of the most salient rhythmic features in current hip-hop music and as such, confirms the continued influence of artists from the American South and Midwest on the hip-hop genre at large. In addition, I show that despite the ostensible regularity and simplicity of its rhythmic surface, triplet flow offers MCs a wide range of metric and rhythmic tools to enhance the expression and meaning of lyrics and imbue their performances with markers of virtuosity and creativity. Exploring markers of virtuosity and creativity in triplet flow examples helps illustrate how a decidedly simple rhythmic unit and its inherent metrical properties can be manipulated, multiplied, and negated in the service of rhetoric and expressivity. ${ }^{6}$

\footnotetext{
${ }^{4}$ Throughout this paper I refer to MCs (rappers) by their stage names, and not their given names. Singles from Invasion of Privacy as well as the album itself were nominated for a total of five Grammy awards, and the album broke numerous streaming and sales records (see Caulfield, 2018).

${ }^{5}$ See Butterfield 2006 \& 2011.Butterfield describes motional energy as "the force of momentum with which some musical events are directed toward others' $(2011,4)$.

${ }^{6}$ Many of these observations stem from similar ones made by Adams (2008) and Krims (2000), who both observed that flow and lyrical techniques have become increasingly sophisticated over time. Krims writes that 'since roughly the beginning of the 1990s, [the rhythmic styles of many commercially successful MCs] have progressively become faster and, as it is often put, more "complex" (2000, 49). Adams writes that "the mid-1980s saw a move away from the original topics of rap lyrics ... and a move towards lyrics of increasing complexity, abstraction, and metaphor' (2008, [3]).
} 


\section{Overview, definitions, and types}

I define triplet flow, which can occur in a variety of musical contexts, as any rapped delivery of lyrics where the unit pulse, or tactus, is triple-divided. Most often, these triple divisions occur atop beats that are duple- or quadruple-divided; indeed, the juxtaposition between a triple-divided flow and a duple-divided beat enables the rhythmic interplay essential to triplet flow's character. ${ }^{7}$ Depending on a song's tempo, the triple division could assume the form of quarter-note, eighth-note, or sixteenth-note triplets. ${ }^{8}$ Two songs taken from Kendrick Lamar's 2012 album Good Kid, M.A.D.D. City exemplify some possible contexts for triplet flow. Examples $3 \mathrm{a}$ and $3 \mathrm{~b}$ show excerpts from the first and second verses of the song 'Swimming Pools', which demonstrate Lamar's shift to triplet flow.

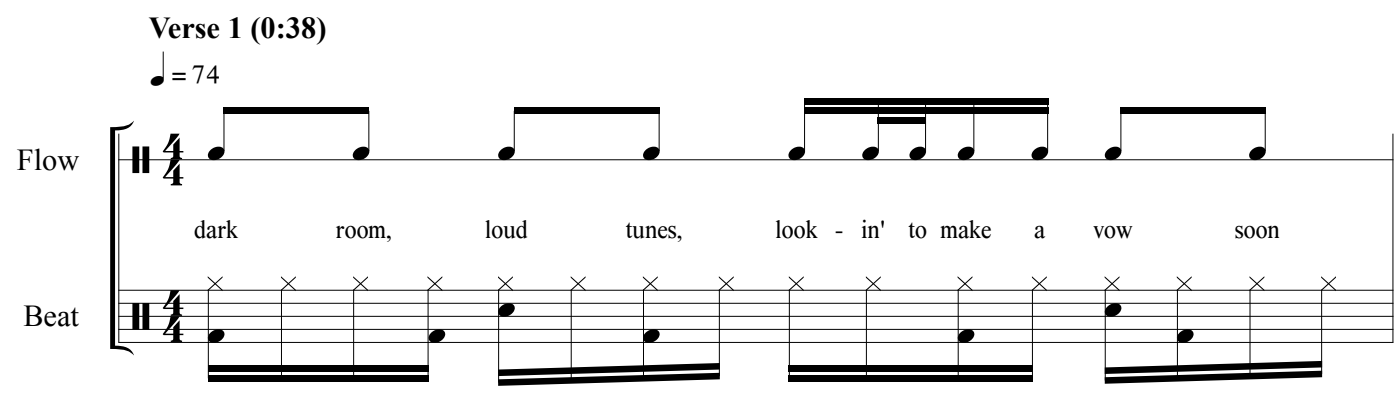

Example 3a: 'Swimming Pools' (Kendrick Lamar, 2012). As detailed here, the duple flow rhythm tightly syncs to the drum pattern shown on the lower staff. Here and in all following examples with two (or more) staves, the upper staff represents the flow layers (rapped vocals), while the lower staves represent all or part of the beat layer (instrumental track), as relevant.

Verse 2 (1:42)

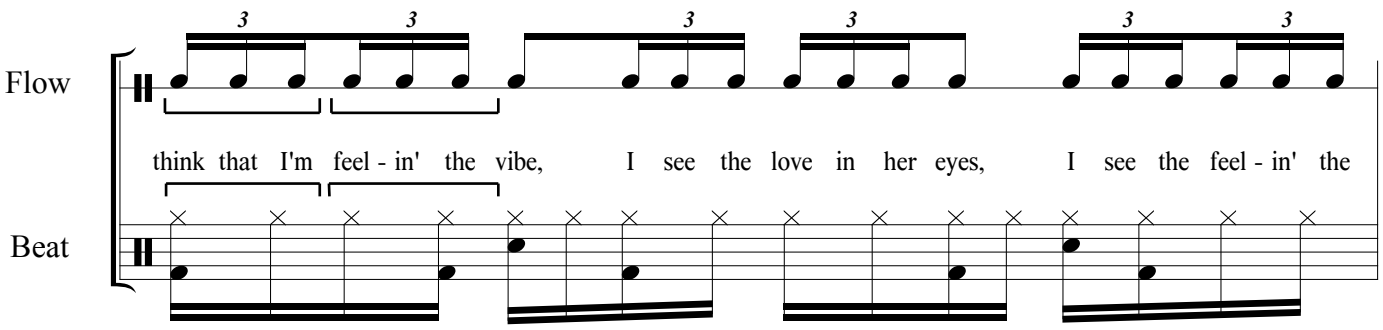

Example 3b: "Swimming Pools" (Kendrick Lamar, 2012). Contrasting Example 3a, here the subdivisions in the flow and beat layers do not always correspond metrically, creating a threeover-two polyrhythm between the triplet flow and the sixteenth-note drum beat, highlighted with brackets in the transcription.

\footnotetext{
7 Though rare, hip-hop songs in compound meter do also exist, notable examples being 'My First Song' (Jay-Z, 2003) and 'Black Skinhead' (Kanye West, 2013). The rhythmic and metric concordance of the triple-divided tactus in both the beat and flow of songs such as these makes them outliers among other examples of triplet flow, where the juxtaposition of duple- and triple-divided tacti persists.

${ }^{8}$ The relationship between tempo, metre-as-heard, and notational representation in popular music has been addressed in detail by de Clercq (2016), who investigates the way listeners' perception of absolute time influences what metre they hear. Since hip-hop lacks a comprehensive notational tradition, I must explicitly account for my own biases when ascribing a metre to the excerpts I transcribe.
} 
As shown in the transcriptions, Lamar raps in duple and quadruple rhythms in the first verse (Example 3a), and triple rhythms in the second (Example 3b). In the song 'Bitch Don't Kill my Vibe' (2012), Lamar switches into triplet flow within each of the first and second verses (an excerpt of the first verse is shown in Example 3c). These examples illustrate the two main contexts where triplet flow tends to occur: in individual phrases as part of a larger formal unit, or across entire formal units such as a verse. (By rarer contrast, triplet flow can also occur in smaller, sub-phrase units, as well as across entire songs.)

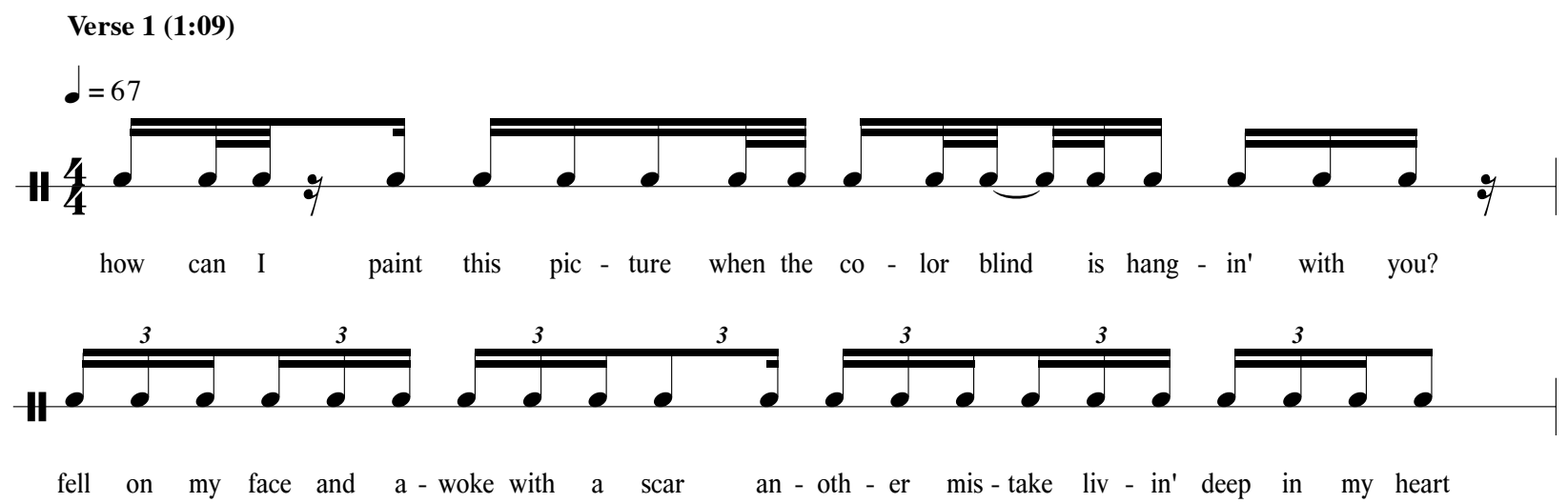

Example 3c: 'Bitch Don't Kill My Vibe' (Kendrick Lamar, 2012). This example details how Lamar switches from duple to triple rhythms within a verse.

We can codify triplet flow according to the extent of its presence in a song. Example 4 provides this codification with explanations and song examples. The first category, mixed triplet flow, refers to occurrences where the triplet flow and a duple-divided flow are mixed at the subphrase level. ${ }^{9}$ For purposes of this study, I define a phrase as a line of lyrics demarcated by either a rhythmic caesura, syntactic closure, a rhyme, or a concurrence of these. Mixed triplet flow features a variable balance of each flow type: some examples use comparatively little triplet flow and are mostly duple, and others the inverse. To my knowledge, most songs with triplet flow released before the early 2000s use mixed triplet flow, such as can be heard in 'Passin' Me By' (The Pharcyde, 1992), 'Nuthin' but a G Thang' (Dr. Dre, 1992), and 'No Surrender' (Bone Thugs-n-Harmony, 1994). The second category, phrasal triplet flow, applies to examples where triplet flow appears for one or more phrases, but not for an entire larger formal unit such as a verse. In recent years this has perhaps become the most common type of triplet flow used in commercial hip-hop music. ${ }^{10}$ Phrasal triplet flow can be used by MCs to change the pacing or accumulation of energy in a verse, or for narrative and rhetorical purposes. The final category, total triplet flow, refers to complete formal units (such as verses) — or rarer, entire songs — where the $\mathrm{MC}$ uses nothing but triplets in their flow. In these examples, the MC must find subtler ways

\footnotetext{
${ }^{9}$ Determining what constitutes a phrase in hip-hop music is a subjective process undertaken by the listener. While the principal punctuations of a line of lyrics are rhymes, syntactic closure and rhythmic caesuras (moments where the flow of lyrics ceases), factors such as metric correspondence with the instrumental beat or song tempo may also play a role.

${ }^{10}$ See Table 2 for evidence of this. In the 50-song corpus used in this study, 38 songs used phrasal triplet flow at some point, compared to 21 using total triplet flow and 4 using mixed triplet flow.
} 
to punctuate and flavour the constant stream of triplets they use, and specific examples of how this can be achieved will be discussed later.

\begin{tabular}{|c|c|c|c|}
\hline Category & $\begin{array}{l}\text { Context of } \\
\text { occurrence }\end{array}$ & $\begin{array}{l}\text { Characteristics and } \\
\text { functions }\end{array}$ & Representative examples \\
\hline $\begin{array}{l}\text { Mixed } \\
\text { Triplet } \\
\text { Flow }\end{array}$ & $\begin{array}{l}\text { Occurs within } \\
\text { phrases, but } \\
\text { does not } \\
\text { constitute entire } \\
\text { phrases }\end{array}$ & $\begin{array}{l}\text { Rhythmic base for a } \\
\text { small collection of } \\
\text { lyrics within a phrase; } \\
\text { used to punctuate } \\
\text { duple-divided } \\
\text { phrases, either to } \\
\text { provide emphasis, } \\
\text { accentuation, } \\
\text { anacruses, or } \\
\text { increased syllabic } \\
\text { density. }\end{array}$ & $\begin{array}{l}\text { - 'Nuthin' But a G Thang' } \\
\text { (Dr. Dre, 1992) } \\
\text { - 'No Surrender' (Bone } \\
\text { Thugs-n-Harmony, 1994) }\end{array}$ \\
\hline $\begin{array}{l}\text { Phrasal } \\
\text { Triplet } \\
\text { Flow }\end{array}$ & $\begin{array}{l}\text { Occurs across } \\
\text { one or several } \\
\text { phrases, but } \\
\text { does not } \\
\text { constitute entire } \\
\text { formal units } \\
\text { such as verses }\end{array}$ & $\begin{array}{l}\text { Rhythmic base for a } \\
\text { phrase, or line, of } \\
\text { lyrics; used to alter } \\
\text { the pacing or motional } \\
\text { energy within a } \\
\text { formal unit, or to } \\
\text { provide a varied } \\
\text { rhythmic template for } \\
\text { rhetoric. }\end{array}$ & $\begin{array}{l}\text { - 'Fight the Power' (Public } \\
\text { Enemy, 1989) } \\
\text { - 'Swimming Pools' } \\
\text { (Kendrick Lamar, 2012) } \\
\text { - 'Bodak Yellow' (Cardi B., } \\
\text { 2018) }\end{array}$ \\
\hline $\begin{array}{l}\text { Total } \\
\text { Triplet } \\
\text { Flow }\end{array}$ & $\begin{array}{l}\text { Occurs across } \\
\text { one or several } \\
\text { complete formal } \\
\text { units (common) } \\
\text { or entire songs } \\
\text { (rare) }\end{array}$ & $\begin{array}{l}\text { Rhythmic base for a } \\
\text { formal unit; used as a } \\
\text { template for varied } \\
\text { approaches to } \\
\text { accentuation, rhyme, } \\
\text { and syncopation. }\end{array}$ & $\begin{array}{ll}\text { - } & \text { 'Dark Sky (Skyscrapers)' } \\
& \text { (Big Sean, 2015) } \\
\text { - } \quad \text { 'Panda' (Desiigner, 2015) }\end{array}$ \\
\hline
\end{tabular}

Table 1: Overview of triplet flow types, characteristics, and examples.

Normally, triplets in the flow layer (the textural layer referring to the rapped vocals) occur simultaneously atop duple-divided rhythms in the beat layer (the song's underlying sampled or instrumental accompaniment). While these simultaneous different divisions of the tactus might not create an audible rhythmic grouping dissonance to every ear, the intricacies of the compound rhythms they create are nevertheless quite audible. ${ }^{11}$ Such a compound rhythm occurs in the second verse of 'Swimming Pools' (Example 3b). The sixteenth-note hi-hat pattern sounds against Lamar's sixteenth-note triplets, adding a layer of rhythmic complexity that was hitherto absent. The timbre and panning of the hi-hat and vocals make them sound very near to

\footnotetext{
${ }^{11}$ I borrow the term grouping dissonance from its use in Harald Krebs' 1999 monograph Fantasy Pieces: Metrical Dissonance in the Music of Robert Schumann. While Krebs uses the term in the context of metric dissonance in the music of Schumann, Nicole Biamonte (2014) applies the concept to rock and pop music, expanding the idea to include rhythmic dissonances: those that do not disrupt the sense of metre in a song.
} 
one another, amplifying the effect of complexity. As will be discussed below, many recent examples of triplet flow occur in songs that use trap beats (defined below in greater detail), where the hi-hat plays a less prominent role in regulating the sub-tactus pulse than it does in many other popular drumming styles. In comparison to the beats used in most hip hop before 2000, trap music (including trap beats used in hip-hop music) features slower tempos, sparser, darker musical textures, and has become emblematic of Atlanta's urban music scene over the past decade. In many songs that combine triplet flow with trap beats, the incessant regularity of the vocalized triplets means that they begin to assume the role as sub-tactus timekeeper (in place of the hi-hat) in the composite texture of the song. ${ }^{12}$

I have defined triplet flow according to the extent to which it occurs (relative to nontriplet flow) in song sections, but these definitions can be expanded upon by considering the flow's internal metric and accentual characteristics. To do so I situate triplet flow within an earlier taxonomy of flow developed by Krims. In his 2000 book Rap Music and the Poetics of Identity, Krims positioned flow in a system of three interconnected styles. He called the first of these 'sung style', describing it as featuring repeated rhythmic groupings, on-beat accents, and rather strict rhyming schemes (usually couplet-based). The second style, 'speech-effusive style' incorporates irregular, complex rhythms and longer strings of rhymes on the same syllable. According to Krims, this style 'feature[s] enunciation and delivery closer to spoken language, with little sense often projected of any underlying metric pulse' (51). Finally, 'percussioneffusive style' uses 'off-beat attacks and a sharply-attacked and crisp [vocal] delivery that accentuates the counter-metric gestures' (52), and can incorporate caesuras, utilize regular rhythmic patterns, but does not necessarily need to be fast-paced. Krims stressed that these three flow styles can, and often do, combine and overlap in hip-hop music.

Emblematic of this overlap, performances of triplet flow can characterize multiple Krimsian flow types simultaneously, mainly exemplifying aspects of sung and percussioneffusive styles. Since triplet flow often uses tightly synced, repeating rhythmic patterns, it generally runs counter to natural rhythms of English speech-which normally alternates long and short durations according to lexical and prosodic stress patterns - thus sounding more like a 'sung-style' flow than a 'speech-effusive' flow. In other cases, triplet flow might highlight counter-metric gestures emblematic of percussion-effusive style but in combination with a legato, smooth vocal delivery, a trait not associated with percussion-effusive style. The songs discussed in this paper (and no doubt many others) typically utilize stylistic features associated with more than one of Krims' three flow types. This alone is not novel, for so do nearly all other hip-hop songs, including those featuring duple-divided flow styles. But triplet flow is perhaps unique in that on the rhythmic surface, its hyper-regular rhythmic groupings (often no more than streams of equally spaced triplets) bear perhaps the closest resemblance to sung style, which Krims (50) associates with old-school hip-hop music. Yet as I will show, beneath this simplistic rhythmic surface lies an organisational complexity not normally associated with sung style, nor with old-school flow styles.

\footnotetext{
${ }^{12}$ Several analytical studies have focused on the metric and musical relationships between flow and beat, notably Adams (2008), Ohriner (2016), and Duinker (2017).
} 


\section{Beginnings and development of triplet flow}

In December 2015, Brooklyn rapper Desiigner (Sidney Royel Selby III) released his debut single 'Panda'. Entering the Billboard Hot 100 chart the following March, by May 'Panda' had reached number one, going four times platinum in the United States by year's end. ${ }^{13}$ While the song was given a boost when Kanye West sampled it on his 2016 album The Life of Pablo, 'Panda's' chart performance still warrants mention given Desiigner's young age (18 years when it was released) and the fact that, other than several releases by Atlanta rapper T.I., trapinfluenced rap songs were relatively rare to appear at the top of the Billboard Top 100 before 2016. ${ }^{14}$ This chart performance also marks the first time a rap song featuring triplet flow reached number one on a non-hip-hop specific chart. ${ }^{15}$ The commercial success of Desiigner and other 'trap rappers' (such as Migos, Future, and Young Thug) has prompted several online media outlets to publish brief surveys of triplet flow in mainstream hip-hop music. ${ }^{16}$ While the most extensive of these surveys (Schmidt et al., 2016) discusses the interregional borrowing in North American hip-hop that facilitated triplet flow's development over time, none of these publications investigate which musical characteristics of earlier triplet practitioners have resurfaced in modern triplet flow. I address this lacuna in the following section by briefly analysing some of the earliest well-known examples of triplet flow in order to unpack the musical blueprints of this style of rapping. I then elaborate on how slower song tempos and the advent of trap music have been instrumental in enabling triplet flow to reach its current popularity.

\section{Early examples}

A handful of artists were experimenting with triplet flow in the late 1980s and early 1990s. Schmidt et al. (2016) cite Public Enemy's 'Bring the Noise' (It Takes a Nation of Millions to Hold Us Back, 1988) as the earliest well-known use of triplet flow. ${ }^{17}$ Chuck D of Public Enemy also uses triplet flow in 'Fight the Power' (Fear of a Black Planet, 1990). Jaz-O and Jay Z, also from New York, released 'The Originators' (To Your Soul, 1990), in which both MCs rap extensively in triplets. On the West Coast, early releases by Dr. Dre (The Chronic, 1992), the Pharcyde (Bizarre Ride II the Pharcyde, 1992), Snoop Dogg (Doggystyle, 1993), and Freestyle Fellowship (Innercity Griots, 1993) use triplets mainly to punctuate passages of duple-divided flow. In the Midwest, Bone Thugs-n-Harmony were experimenting with fast, rhythmically rigid, and sharply articulated triplet flow to popularize a new style of rapping known as chopper rap; a rigid, rhythmic, and fast-paced style of rapping.

\footnotetext{
${ }^{13}$ According to billboard.com, 'Panda' spent 54 weeks on the Top 100 chart. The song eventually reached five times platinum in mid-2017, according to the Recording Industry of America (riaa.com).

14 Though since 2016, they have become more prevalent on the Billboard charts. Molanphy (2016) explores how Kanye West's involvement helped 'Panda' reach number one, suggesting that this success might herald a new era of hitmaking, presumably where resampling a record can give it renewed and greater exposure. Both Molanphy and GQ's Music Column (2016) also situate Desiigner's musical style as descending from Atlanta rapper Future, known for his use of triplet flow and trap beats. (Triplet flow is, however, not mentioned in either writing.)

${ }^{15}$ By the time 'Panda' reached number one on the Hot 100 chart, it had already been number one on the Hot Rap Songs chart for some time, unseating G-Eazy and Bebe Rexha's 'Me Myself \& I' (2015), another rap song featuring heavy use of triplet flow (Mendizabahl, 2016).

${ }^{16}$ See Drake 2014, Schmidt et. al 2016, and Caswell 2017.

${ }^{17}$ Earlier, shorter examples of triplet flow can be found in 'Planet Rock' (Afrika Bambaataa and Sonic Soul Force, 1982), 'Roxanne Roxanne’ (UTFO, 1984), and 'Roxanne’s Revenge’ (Roxanne Shanté, 1984).
} 
Three songs released during hip-hop music's Golden Age (a period between approximately 1986-1993 in which the stylistic diversity and commercial supremacy of hip-hop music made dramatic gains) serve well to evaluate the diversity in early triplet flow practice. Crucially, these songs all have tempos close to 100 beats per minute (bpm), markedly faster than most songs discussed later in the paper. ${ }^{18}$ In 'Fight the Power' (1990), Public Enemy's Chuck D raps most of the third verse in a free-flowing mixed triplet flow, delivering groups of three syllables over each quarter-note pulse, as transcribed in Example 4. ${ }^{19}$

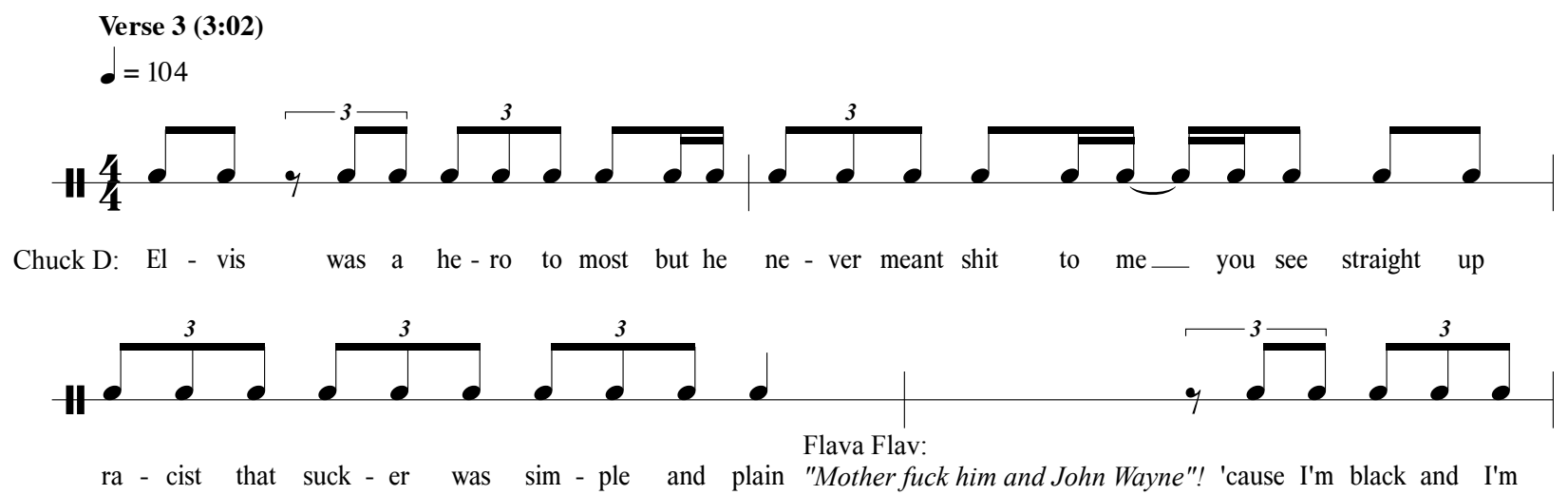

Example 4: 'Fight The Power' (Public Enemy, 1989). Chuck D's performance of this passage, while energetic, adopts a more relaxed feel than he uses in the two other verses of this song. The transcription here, even more so than other examples in this paper, represents an approximation of Chuck D's vocal rhythms, as his flow often includes microtiming variations and slight lags from the rigid triplets implied by the notation above.

'Fight the Power' proceeds at a tempo of $104 \mathrm{bpm}$, one of the fastest of any song discussed in this paper. At this tempo, rapping in sixteenth-note triplets (such as Kendrick Lamar did in Examples 3b and c) would be uncharacteristic of Chuck D's speech-effusive flow styleand the lyrics would be near-incomprehensible. Tempo considerations aside, this verse can be viewed as a sharp contrast in flow style from the first two verses in 'Fight the Power'. While Chuck D's flow in the first verse sounds the most declamatory — with frequent caesuras and

\footnotetext{
${ }^{18}$ I determine tempo according to the kick/snare backbeat pattern of the drums in the beat layer of each song. (See Biamonte 2014, [6.1] for an overview of the backbeat pattern's importance to metre and tempo in rock music in particular.) De Clercq (2016) defends the practice of determining measure length, and by extension song tempo, using absolute time as a determinant, citing perceptual studies that have shown a two-second timespan to be the ideal duration for experiential measures in listening subjects. While de Clercq's findings are compelling, two factors led me to part from them in my determinations of tempo and measure lengths here. First, his chosen repertoire is pop and rock music. In general, these styles contain much more variance in phrase length of vocal lines, harmonic rhythm of accompaniment, and rhythmic variation of drum patterns than is found in hip-hop music. Second, the perceptual studies de Clercq cites mainly focus on tapping experiments. I posit that a more reliable indicator of tempo and measure perception would include a more embodied response to the audio stimuli, such as dancing. While I know of no studies that do this with respect to hip-hop music, I hypothesize that the results would show a more faithful correspondence to backbeat patterns as determinants of tempo, and by extension, measure.

${ }^{19}$ Robert Walser (1995) provides a close reading of rhythm and rhetoric in 'Fight the Power', including the tripletised third verse, but makes only brief mention of the triplets themselves. His reading of this song highlights the connection between vocal rhythm, lyrics, and rhetoric in these three verses, and shows how a discussion of variegated rhythmic practices of rappers can support the narrativity and rhetoric of a song's lyrics.
} 
longer-held syllables - and his flow in the second sounds denser and more syncopated, the third verse, where triplet flow is used, sounds perhaps the most relaxed.

'Nuthin' But a G Thang', the lead single from Dr. Dre's 1992 album The Chronic, can be used to demonstrate the variety of triplet flows already used in the early 1990s. This song features triplet flow, but in a markedly different setting than in 'Fight the Power', despite being only slightly slower $(95 \mathrm{bpm})$. Here, as Example 5 details, the triplets - sparse as they arerapped by Snoop Dogg function more as agents of anacrusis or accent atop a duple-divided rhythmic base, perhaps as though triplets are used in place of sixteenth notes in order to 'fit in' more syllables. ${ }^{20}$ This type of mixed triplet flow occasionally turns up in the rapping of other West Coast artists active in the early and mid 1990s, among them Freestyle Fellowship and the Pharcyde. ${ }^{21}$

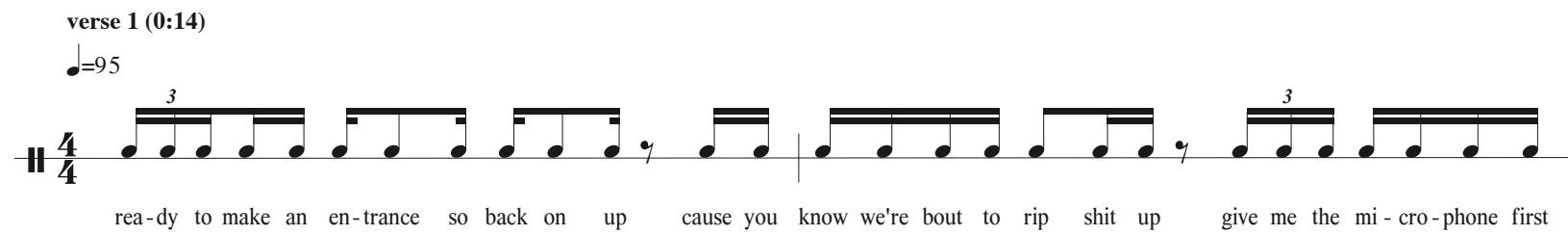

Example 5: 'Nuthin' But a G Thang' (Dr. Dre, 1992), constituting an early example of mixed triplet flow.

In 1993, Cleveland-based B.O.N.E. Enterpri\$e released their debut album Faces of Death. That same year, Los Angeles-based MC and record executive Eric Wright-better known as Eazy-E_-signed the group to his Ruthless Records label, changed the group's name to Bone Thugs-n-Harmony, and launched their career as a top-charting act. Bone Thugs-n-Harmony's success helped popularize the rigid, rhythmic, and fast-paced style of rap known as chopper rap. ${ }^{22}$ Chopper rap's connection to triplet flow can be heard on Bone Thugs-n-Harmony member Krayzie Bone's verse in 'Flow Motion' (1993), a short excerpt of which is transcribed in Example $6 .{ }^{23}$ At $100 \mathrm{bpm}$, this song runs slightly slower than the two discussed above, but the

\footnotetext{
${ }^{20}$ Snoop Dogg's use of triplet flow in this excerpt is what Gomez-Peck (2019) describes as incidental triplet flow; a 'crushed rhythm' of extra syllables to fit into a beat.

${ }^{21}$ Examples of such rapping can be found in 'Nuthin' but a G Thang' (Dr. Dre and Snoop Dogg, 1992) and 'Passin' Me By' (The Pharcyde, 1992). Despite being an early incorporator of triplets into his personal flow, Snoop Dogg has been vocally critical of what he views as a homogeneous assortment of triplet flows in recent rap (see Cowell, 2015).

${ }^{22}$ Bone Thugs-n-Harmony's earliest forays into chopper rap and triplet flow were likely influenced by their exposure to the underground hip-hop scene in Los Angeles, mainly centered at the Good Life Cafe (now closed). In particular, there is speculation that Bone Thugs-n-Harmony co-opted and popularized the flow styles of, in particular, the L.A.-based Freestyle Fellowship. This topic is briefly discussed in Ava DuVernay's 2008 film This is the Life, which chronicles the significance and influence of Los Angeles's underground hip-hop community. Through an email conversation with hip-hop scholar Charles Sharp, I learned that among the Good Life community, the story of Bone Thugs-n-Harmony's co-opting of Freestyle Fellowship's style is widely believed and corroborated. Though extensive, interview-based fieldwork would generate more certainty in this regard, it lies beyond the scope of this paper. Whether or not Bone Thugs-n-Harmony did start using triplet flow after hearing it performed at the Good Life Cafe, the group's innovative use of it on their records throughout the 1990s did much to popularize it and expose it to a wider audience.

${ }^{23}$ This verse of 'Flow Motion' is the earliest example I can locate where such a long uninterrupted stream of phrasal triplet flow occurs. All contemporary and earlier examples are better described as displaying the mixed triplet flow type.
} 
substantial passage of sixteenth-note triplets performed by Krayzie Bone imbues this example of triplet flow with a different rhetorical function than 'Fight the Power' or 'Nuthin' But a G Thang': one of urgency, but also consequently one of braggadocio with regards to the skill required to rap in sixteenth-note triplets at this tempo.

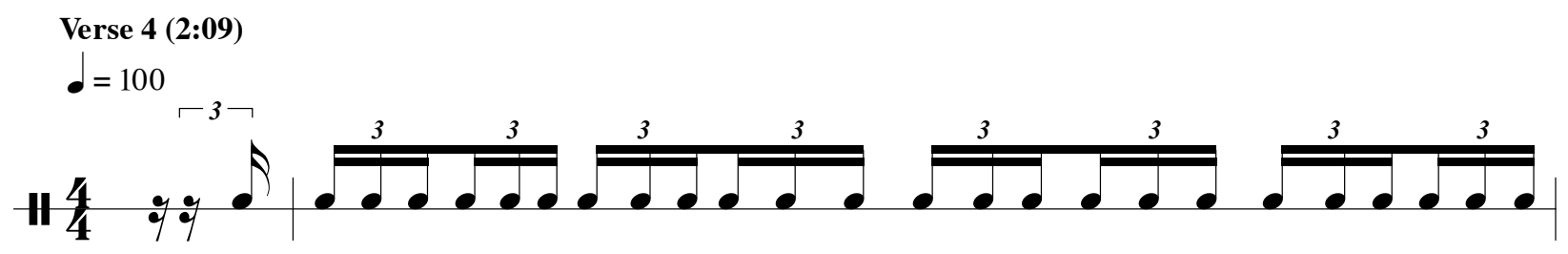

There's ne-ver an-oth-er to go with a bro-ther while smu-ther-in' suck-ers been goin' un-der-co-ver we

Example 6: 'Flow Motion' (B.O.N.E. Enterpri\$e, 1993). Krayzie Bone's delivery of this passage is nearly unintelligible due to the speed required to perform the lyrics at the tempo of $100 \mathrm{bpm}$.

To summarize these examples, three distinct profiles of triplet flow appear to have emerged already by 1993. In 'Fight the Power', Chuck D uses triplet flow to contrast his more declamatory and syncopated flow styles of earlier verses, resulting in a more relaxed, constant, and balanced style of flow. In 'Nuthin' But a G Thang', the triplet flow gets used as a means to vary the rhythmic composition of the verse, and to highlight accents, syncopations, and rhymes in the lyrics. In 'Flow Motion', triplet flow aggressively fits as many syllables as possible into a constant stream of triplets, where the flow style becomes less about lyrical intelligibility and more about displaying vocal dexterity. As such, the triplet flow of 'Flow Motion' aligns closest with Krims' percussion-effusive style, while Chuck D’s flow perhaps aligns closest with speecheffusive style. The three approaches to triplet flow detailed here occur in songs of roughly equal tempo. As hip-hop song tempos got increasingly slower through the 1990s, these three profiles became less distinct, but triplet flow on the whole has continued to provide a rhythmic template for the associated characteristics of these profiles: relaxedness, balance, accent, anacrusis, syncopation, and speed.

\section{Hip-hop music slows down}

Through the early and mid 1990s, hip-hop song tempos became increasingly slower. ${ }^{24}$ In 'Fight the Power' and 'Flow Motion', at tempos around 100 bpm, Chuck D's eighth-note triplets sounded slow and relaxed, and Krayzie Bone's sixteenth-note triplets sounded so rushed as to border on incomprehensible. With tempos of $75 \mathrm{bpm}$ or lower, sixteenth-note triplets, expectedly, become easier to vocalize, and lyrics become more intelligible to listeners. Whereas at $100 \mathrm{bpm}$, sixteenth-note triplet flow often sounds rushed and emotionally charged, at $75 \mathrm{bpm}$ MCs have greater choice regarding whether to imbue their triplet flow with a more relaxed feel. Furthermore, with the possibility of more intelligible lyrics, the triplet flow becomes less about speed and vocal dexterity, and more about engaging with rhetoric and narrativity.

\footnotetext{
${ }^{24}$ Evidence supporting this observation appears in Condit-Schultz 2016 and Duinker \& Martin 2017. The downward trends found in these publications are reflected in mean tempo values for corpora of songs; of course, many hip-hop songs with outlying tempos were, and still are, produced.
} 
By the mid-1990s, triplet flow had been popularized by Bone Thugs-n-Harmony and the Memphis group Three 6 Mafia; these groups exert perhaps more stylistic influence on modern triplet flow than any other artist active before 2000. Bone Thugs-n-Harmony's breakthrough album E. 1999 Eternal (1995), released in the wake of their mentor Eazy-E's death, built on the success of their EP Creepin' on ah Come Up (1993). The leading singles from each (respectively), 'Tha Crossroads' and 'Thuggish Ruggish Bone' cast triplet flow into the spotlight, especially after 'Tha Crossroads' won the Grammy Award for Best Rap Performance (1997) and topped the Billboard Hot 100 chart. These hits, along with songs such as '1st of tha Month' (1995) and 'No Surrender' (1994) put on display Bone Thugs-n-Harmony's signature blend of chopper rap and triplets: rhythmically rigid, fast, and on-beat triplet flow. Krayzie Bone's verse in 'No Surrender' (excerpted in Example 7) offers a representative example of triplet flow as Bone Thugs-n-Harmony rapped it in the mid-1990s: mixed with duple and doubletime flow, triplets are an integral part of the rhythmic composition, but rapidly interchanged with other rhythms, with some sections sung rather than rapped.

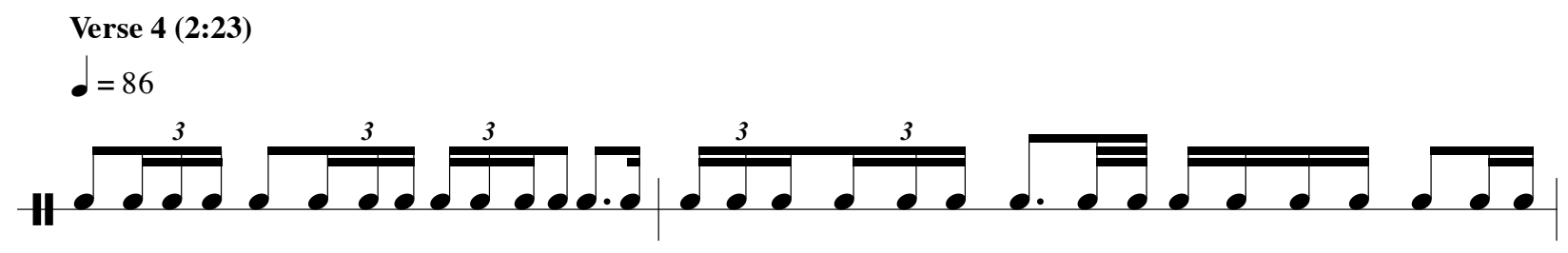

mine e-ver-y time this-'ll be o-ver in 9-9 so nig-ga get down for the crime gon-na be more cop-pers dyin' in the

Example 7: 'No Surrender' (Bone Thugs-n-Harmony, 1994). As demonstrated by the excerpt, this verse features an intricate mixture of rhythmic divisions, characterized as mixed triplet flow.

While Bone Thugs-n-Harmony was mixing chopper rap, triplet flow, and singing, Three 6 Mafia was cultivating an aggressive, dark, menacing style of rap that eventually became known as crunk. $^{25}$ Three 6 Mafia's musical signatures include drum beats made with the Roland TR-808 drum machine, deep, synthesizer-generated bass lines, and repetitive, chanting vocals often including triplets. Though Three 6 Mafia member Lord Infamous used triplet flow as early as 1993, the 1999 track 'Sleep', partially transcribed in Example 8, features a more mature and tightly-organized version. ${ }^{26}$ Lord Infamous delivers the first verse entirely in triplet flowrepresenting the earliest examples of total triplet flow of which I am aware - using balanced, symmetrical phrasing. Each rhyme pair forms a couplet, and no syncopation or internal rhymes interfere with the phrasal symmetry.

\footnotetext{
${ }^{25}$ Crunk is today most often associated with Atlanta-based Lil' Jon and the East Side Boyz, known for crunk anthems such as 1997's 'Who U Wit' and 2003's 'Get Low'.

${ }^{26}$ Schmidt et al. (2016) cite Da Serial Killaz (Lord Infamous and DJ Paul, 1993) as one of the earliest examples of Lord Infamous using triplet flow.
} 


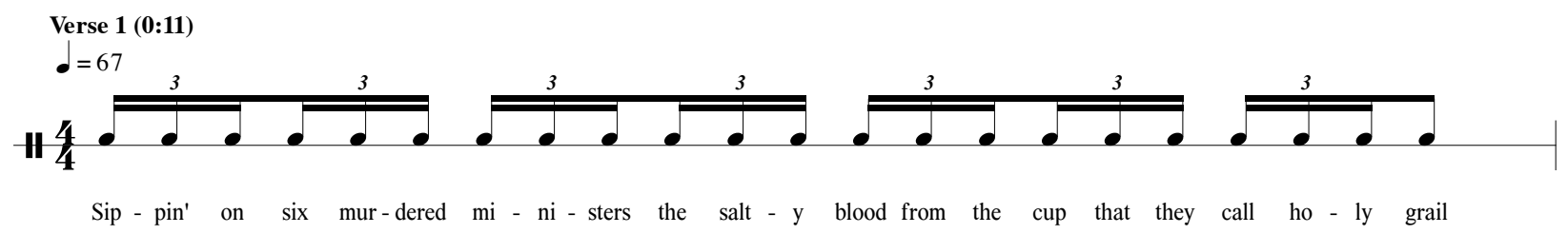

Example 8: 'Sleep' (Three Six Mafia, 1999). Lord Infamous raps with little variance in pitch, articulation, or volume. This lack of variance exposes the propelling, energetic, yet almost mechanical qualities of triplet flow.

The constant stream of triplets in Lord Infamous' performance imbues this verse with a sense of energy and urgency that belies its relatively slow tempo of $67 \mathrm{bpm}$, even despite the rhythmic, metric, and formal simplicity detailed in the transcription. This urgency becomes more salient when compared to the fifth verse of 'Sleep' (3:09, rapped by Juicy J), where the absence of triplets - or indeed any regular recurring rhythmic unit—fails to create the same effect. I do not wish to construe this comparison as a value judgement; rather, it illustrates how a regularly occurring triplet rhythm can imbue motional energy to a musical phrase. The term 'motional energy' comes from the work of Matthew Butterfield, who defines it as 'the force of momentum with which some musical events are directed toward others' (2011,4). Adapting Butterfield's definition for this paper, I construe it as the level of energy with which the flow propels toward or anticipates the following downbeat or hyperdownbeat (downbeats occurring at the hypermetrical level). Thus, while flows that incorporate rhythms of differing values might imbue a phrase with increasing and decreasing motional energy, triplet flows - containing constant triplet rhythms - quite often seem to propel forward toward oncoming downbeats, the motional energy constantly accruing and increasing.

\section{Trap music and the current popularity of triplet flow}

While hip-hop music originated and first flourished in the American Northeast, and was eventually dominated by two poles, New York and Los Angeles, by 2000 Atlanta (and the South in general) had become a major regional player in the hip-hop music landscape. ${ }^{27}$ Three factors associated with the South's increasing importance to this genre paved the way for the more recent popularity of triplet flow. ${ }^{28}$ First, the success of Atlanta duo Outkast meant that other Southern artists began to enjoy increased commercial and critical attention, albeit gradually. ${ }^{29}$ Second, the importation of the crunk sound from Memphis to Atlanta and its subsequent

\footnotetext{
${ }^{27}$ Sarig (2007) and Grem (2006) dissect the South's rise to prominence in detail, with Sarig focusing on several geographic sub-regions.

${ }^{28}$ While not cited as a major event associated with the South's increasing importance in hip hop, Three 6 Mafia's 2006 Academy-Award-winning song 'It's Hard Out Here for a Pimp' elevated the group's status in the hip-hop industry from underground sensation to leading act, and likely brought increased awareness to the group's early triplet flow efforts.

${ }^{29}$ To be sure, Outkast was not solely responsible for increased exposure of Southern hip-hop artists, but their 1995 Source Award for best new artist and three Grammy Awards for Speakerboxx/The Love Below (2003) were instrumental in exposing Southern hip-hop to a wider audience. Sarig (2007) suggests a loose coordination between Outkast's trajectory and the greater fortunes of Southern hip-hop, writing that 'the group's arrival coincided with the birth of a Southern sensibility in hip-hop, and its peak heralded the era where Southern hip-hop dominated American pop' (340).
} 
increased popularization by artists such as Lil' Jon preserved Atlanta's status as the centre of southern hip-hop. Third, and most recently, the emergence and popularity of trap beats - slower, texturally sparser, and more bass-heavy than those found on crunk records - coincided with the rise in prevalence of triplet flow (which I believe not to be coincidental, as described below). Writing in 2007, Roni Sarig proclaimed that the 'era of Southern hip hop is over' (337), suggesting that Southern hip-hop artists were growing less and less distinct from those of other regions. While this may be true in a general sense-hip-hop music is arguably becoming increasingly less regional in the internet age - much of the ensuing homogeneity has come from artists in other regions emulating stylistic traits that have been percolating in the South for some time. ${ }^{30}$

Trap music borrows the term 'trap' from describing 'street life centred on dead-end hustles and other fast tracks to jail or the morgue' (Sarig, 210). ${ }^{31}$ Trap beats are characterized by the deep sub-bass lines and 808 beats (drum beats produced by the Roland TR-808 drum machine) also found in Three 6 Mafia's 1990s releases, supplemented by synthesizer-driven string lines, minor and diminished harmonic sonorities, slower tempos, and inconsistent hi-hat patterns. (If they follow a more regular rhythmic pattern, the hi-hat parts are occasionally brought down in the audio mix relative to the kick and snare drums.) The texture of these beats is often quite sparse, with a tempo range of approximately $60-75 \mathrm{bpm} .{ }^{32}$ These two musical characteristics are crucial. As mentioned earlier, slower tempos are easier to rap over (especially in triplets). Beat textures made sparse through the absence of regular hi-hat patterns tend to lack a constant sub-tactus pulse. The regularity and consistency of triplet flow fills this textural gap quite naturally, resulting in a flow layer that not only facilitates the lyrics but regulates the temporal aspect of the entire song. Atlanta-based Young Thug's 'With That' (2015, partially transcribed in Example 9) exemplifies how triplet flow and trap beats complement one another almost naturally. The song has a tempo of $62 \mathrm{bpm}$, features a relatively sparse instrumental texture (the synths notated in the transcription are never all that loud in the track), and lacks a constant hi-hat pattern in the beat. On top of this beat, Young Thug raps constantly in triplet flow, with ample freedom to establish different phrase structures over this sparse, slow beat. ${ }^{33}$ But through a varied phrasing structure, his triplet flow maintains enough consistency to be able to function as the primary sub-tactus pulse layer in this song, assuming the role usually filled by the hi-hat.

\footnotetext{
${ }^{30}$ See Weiner (2012), Lee (2014), and Setaro (2016) for arguments about why hip-hop music has become less regional in recent years. Lee specifically cites rap scholar Murray Forman as stating that 'the internet has facilitated a sense of placelessness.' Two factors (among presumably many) contributing to this 'post-regionalism' include the ubiquity of the internet enabling MCs and beatmakers to more easily collaborate remotely, and Soundcloud and other music sharing platforms enabling hip-hop artists to connect with and form communities that are not tied specific locales.

${ }^{31}$ In addition, a 'trap house' can be considered synonymous with a 'crack house' or 'drug house'; houses where drugs are manufactured, used, and occasionally sold.

${ }^{32}$ This tempo range could also be construed as $120-150 \mathrm{bpm}$, if the unit pulse is taken to be twice as fast. In choosing to notate examples in the $60-75 \mathrm{bpm}$ window, my attention to backbeat drum patterns influences my decision. De Clercq (2016) questions the usefulness of this approach and shows many situations where absolute time is a more accurate and reliable method for determining measure length. My reasons for preferring the slower tempos here are several. First, it means that across the whole paper, my notation remains consistent, in that the backbeat pattern is always used to determine a measure of common time. And second, textural and harmonic aspects of the beat layer in these 'slower' beats often suggest a hearing in the slower tempo.

${ }^{33}$ Aside from using triplet flow often, Young Thug's other vocal signatures include near-constant use of autotune and partially-incomprehensible lyrics.
} 


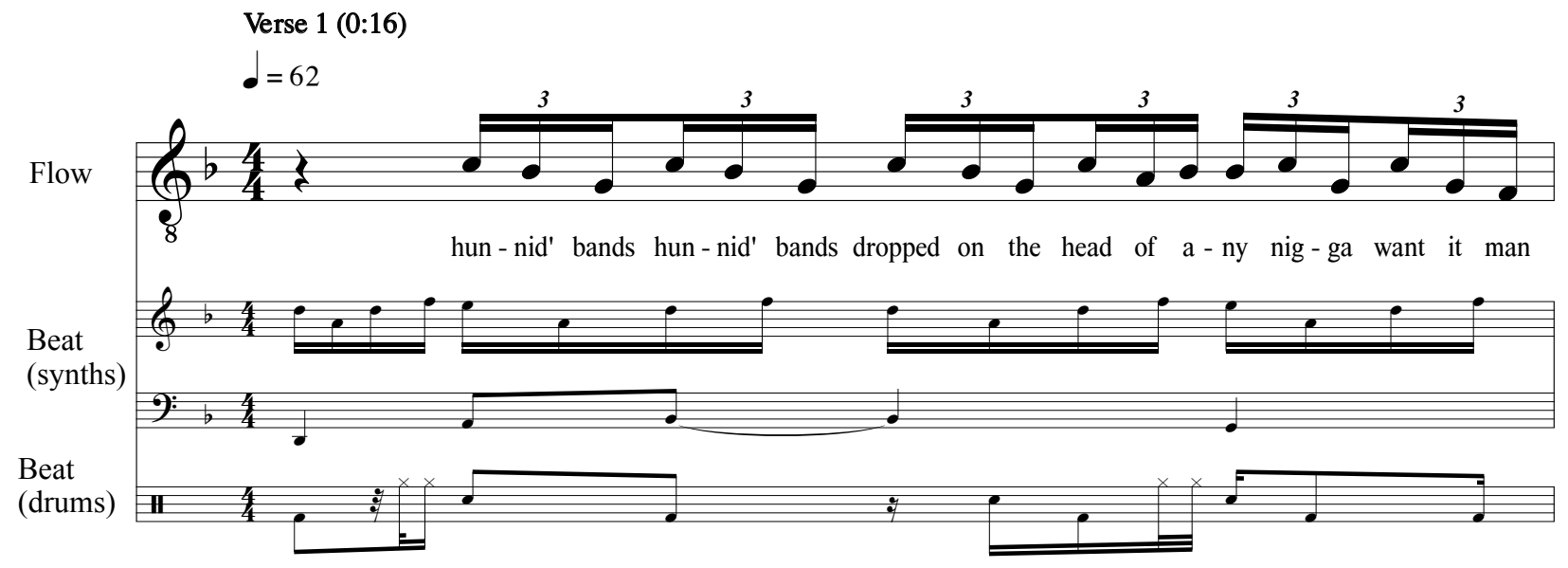

Example 9: 'With That' (Young Thug, 2015). Young Thug's signature style includes auto-tuned sing-rapping and frequent use of triplet flow. In this example, the beginning of each line of lyrics is displaced from the metrical downbeat established by the beat layer.

Trap music's popularity over the past decade represents the final phase in triplet flow's evolution from an occasionally used and non-codified rhythmic technique in the late 1980s and early 1990s to a signature feature of Southern hip-hop's current hegemony over the genre at large. Triplet flow's popularity is easy to gauge. David Drake (2014) suggested that the rapper Quavo (of Atlanta-based Migos) was the most influential rapper of 2014 on account of his triplet flow in the group's single 'Versace' (2013). Despite being versatile MCs who have cultivated idiosyncratic flow styles, both Kendrick Lamar and Big Sean use triplet flow on some of their early singles, 'Swimming Pools' (2012) and 'Blessings' (2015) respectively. Other artists who regularly use triplet flow such as Young Thug, Drake, Meek Mill, G-Eazy, and Future also enjoy frequent chart success with their singles. And finally, Desiigner's and Cardi B's spells at the top of the Billboard Hot 100 since 2016 have perhaps cemented this flow's dominant status in commercial hip-hop music. 


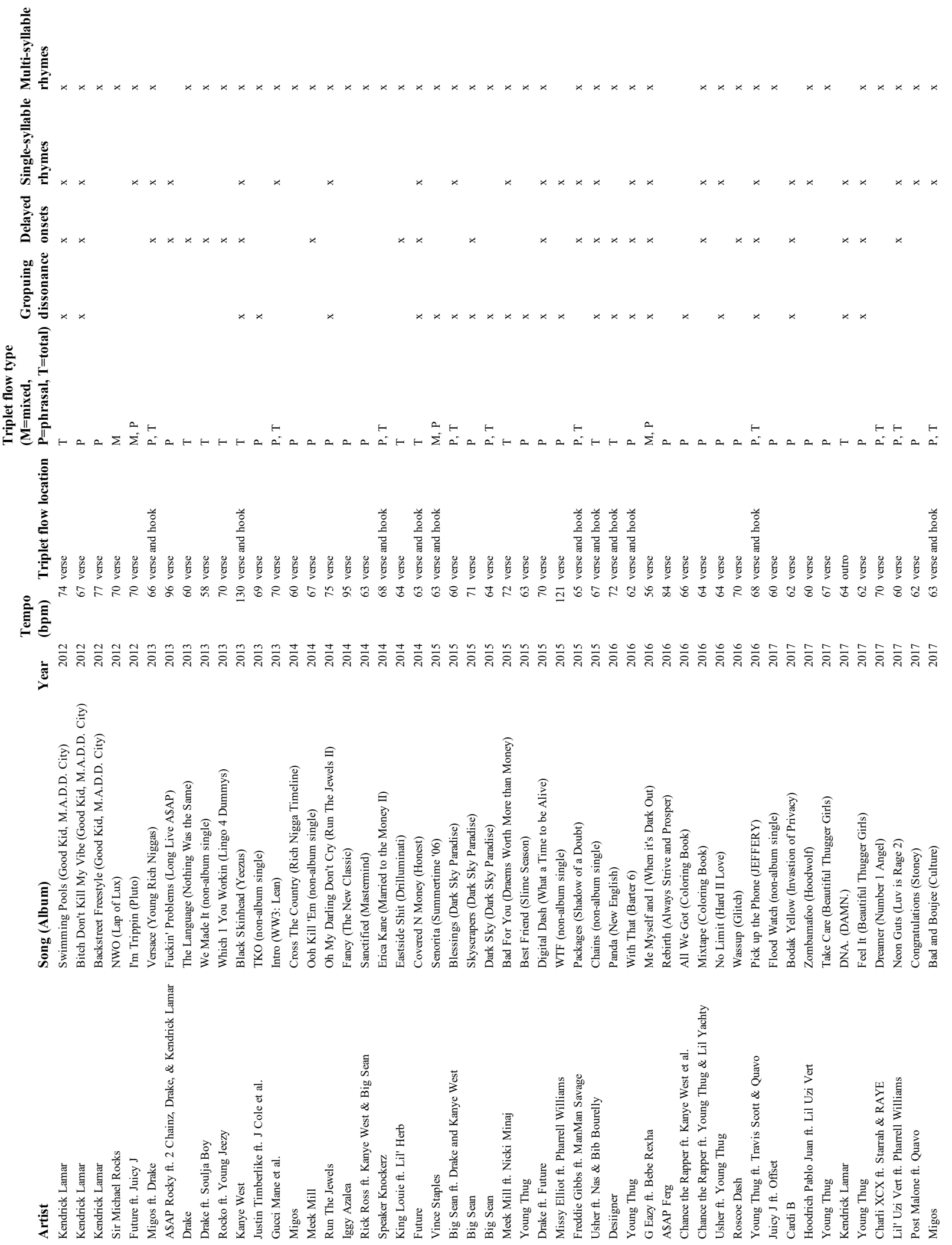

Table 2: Fifty-song mini-corpus. 


\section{General stylistic properties}

Certain musical norms prevail in many of the more recent songs featuring triplet flow. In order to substantiate this observation, I assembled and analysed a fifty-song corpus, detailed in Table $2 .{ }^{34}$ Released between 2012 and 2017, these fifty songs exhibit several common characteristics. First, with only five exceptions, their tempos fall between 58 and $75 \mathrm{bpm}$. This figure mirrors my observation made earlier that over beats up to $75 \mathrm{bpm}$, rapping in triplets is not prohibitively difficult, affording variegated phasing possibilities to the $\mathrm{MC}$ and offering intelligible lyrics to the listeners. ${ }^{35}$

Second, while all 50 songs use triplet flow in verse sections, only eleven songs use it in hook sections (in hip-hop journalism and scholarship, the term 'hook' is often used instead of 'chorus'). When we consider the increasing prevalence of verse/hook-alternating song forms in hip-hop music over time, triplet flow's ubiquity in verses seems more natural: choruses or hooks in commercial popular music - hip hop included - tend to have simpler, more repetitive lyrical and rhythmic structures, in order to be catchier and more memorable. ${ }^{36}$ The prevalence of dupledivided hooks in this corpus suggests an analogy to David Temperley's 'loose-verse tightchorus' model for formal sections in rock (2007). Temperley found that the pitch content of chorus melodies fit more tightly with the harmony that underlays them (dissonances resolve properly, and fewer non-chord tones are used) than that of verses. Adapting this dichotomy to the rhythmic plane, we could suppose that because of the inherent tension between triple- and dupledivided tacti that occurs with triplet flow atop duple-divided beats, duple-divided vocal rhythms seem to work better in hook sections, while triplet flow works better in verses, producing 'unified' and 'stratified' (Temperley's terms) rhythmic textures, respectively. ${ }^{37}$

Third, approximately half of the songs in the corpus feature metric displacement or grouping dissonances between the flow and beat. Displacement dissonances, as formalized and described by Harald Krebs, involve an interaction of metric layers (in this case beat and flow) whose lengths, or cardinalities, are identical or multiples of one another, but whose start and endpoints are misaligned $(1999,34)$. Displacement dissonances in triplet flow usually assume the

\footnotetext{
34 The corpus was assembled using songs referenced in Caswell 2017 and Drake 2014 and supplemented with additional songs.

${ }^{35}$ Condit-Schultz (2016) found that while average song tempo in hip-hop music has decreased over time, average rap speed (measured in syllables per second) has remained relatively constant, suggesting that MCs rap more syllables over slower beats. The two songs with tempos around 100 bpm discussed earlier ('Fight the Power' and 'Flow Motion') feature, in general, sixteenth-note based flows (excepting where triplet flow occurs), meaning that if each sixteenth note were occupied with a syllable, the syllabic rate of these flows would average 6.67 syllables per second (slightly higher than Condit-Schultz's found average of 4.5 syllables per second). Rapping sixteenth-note triplets in a tempo range of 60-75 bpm would produce a window of syllabic density between 6 and 7.5 syllables per second; again, higher than Condit-Schultz's average, but certainly within the capability of many MCs. This suggests that triplet flow in this tempo range is perhaps faster than the average rap speed of most MCs, but not so fast as to compromise clean and intelligible vocal delivery. Syllabic densities in the 6 to 7.5 syllables per second range may also correspond to the natural cadence of the English language. Though accurate calculations of the general, average spoken speed of a language are impossible to produce, various specific studies on the topic have been conducted. For example, in a comparative study of seven spoken languages, Pellegrino et al. (2011) found an average speech rate of 6.19 syllables per second for the English language, not far from the rates discussed above.

${ }^{36}$ Throughout hip-hop's Golden Age, Duinker \& Martin (2017) observed a general move away from strophic song forms toward verse-hook forms.

${ }^{37}$ Krims (2000, 85-86) suggests that hip-hop's gradual adoption of R\&B-style choruses, including sung vocals, occurred in the mid-1990s, with the advent of what he calls Don rap: a blend of two of his four genres, reality rap and mack rap.
} 
form of delayed vocal entries, where a metric unit of flow (typically lasting one measure in $4 / 4$ time) begins later than the metric unit of the beat that underlies it. These units of vocals can either straddle two metric units of the beat layer, such as in the first verse of 'Best Friend' (Young Thug, 2015, Example 12). Alternatively, these units of vocals might end in sync with the unit of the beat that underlies them, such as in the hook of 'With That' (Young Thug, 2015, Example 9). Grouping dissonances describe situations where, through the organization of rhymes and caesuras, the metric units generated by the flow layer are of different lengths or cardinalities than the units of the beat layer. A common example of this phenomenon occurs when units of flow are organized in the tresillo beat pattern $(3+3+2)$ or double tresillo beat pattern $(3+3+3+3+2+2)$ over equally divided measures of the beat - those that do not exhibit tresillo-like grouping structure. These dissonances are illustrated in more detail in subsequent musical examples.

The fourth characteristic concerns rhyming patterns. Few songs in the corpus feature single-syllable rhymes; most feature a combination of single and multi-syllable rhymes, or multisyllable rhymes only. To be sure, single-syllable rhymes could be rarer in all hip-hop music. But the high prevalence of multi-syllable rhymes in this corpus suggests that MCs are aware that rhyming two or three syllables across a triplet figure works well. This in turn suggests that the triplet rhythms are already in the mind of the MC when the lyrics are composed. Contrasting this observation with the declamation patterns of older hip-hop music-where rap vocal rhythms are constructed so that lexical stresses and natural speech rhythms are preserved-it appears that in many recent songs using triplet flow, natural speech rhythm and stresses are of secondary importance to the triplet-driven rhythms. The following examples illustrate how these characteristics engage with one another in individual songs from the corpus.

\section{Characteristic examples}

The first verse of 'Me Myself \& I' (G Eazy ft. Bebe Rexha, 2015) exemplifies multisyllable rhymes, delayed vocal entries, and grouping dissonance. For instance, the rhymes that open the first verse (0:26) occur in groups of three syllables over a triplet figure; the lyric 'I can see' rhymes with 'pri-va-cy', and 'lot of tree' rhymes with 'mo-de-sty'. The lyrics and flow in this verse are organized in two-measure phrases. Each of these phrases begins slightly after the hyperdownbeat of the beat layer that underpins them. The lyrics 'and as far as I can see' begin on the second quarter note of the beat's two-measure loop. Concluding with the lyrics 'try-na see', this phrase ends immediately before the ensuing hyperdownbeat of the beat layer, and thus any caesura that would separate this phrase from the next one would have to - and does-occur at the beginning of the next two-measure loop of the beat. The third phrase (shown in Example 10) exemplifies a grouping dissonance between flow and beat layers. As the brackets grouping the sub-phrases of lyrics detail, the phrase divides into four groups of three eighth notes followed by one group of four eighth notes, creating a $3+3+3+3+4$ (a variant of the double tresillo) pattern over the evenly-divided beat layer. The sub-phrases in the flow layer are easily heard when paying attention to the rhyme scheme here: again using multi-syllable rhymes, G-Eazy demarcates sub-phrases with the lyrics 'be alone', 'be at home', 'speakin' on', 'need a loan', and 'keepin' on' (all highlighted in Example 10). 

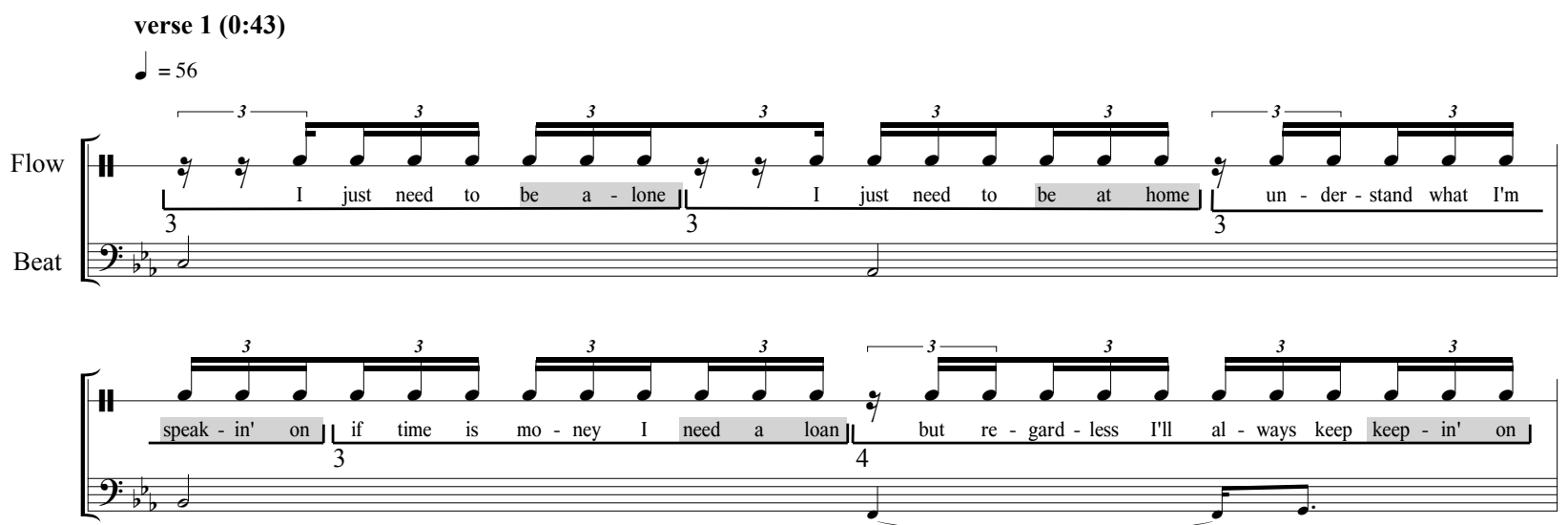

Example 10: 'Me Myself \& I' (G Eazy, 2015). Multi-syllable rhymes are shaded. Represented here with the recurring bass line, the beat layer repeats a loop of two measures. Atop each iteration of this loop, the flow enters delayed by various durations. This excerpt shows the double tresillo grouping $(3+3+3+3+4)$ of the lyrics, creating a grouping dissonance with the harmonic rhythm of the bass line.

A more intricate example of grouping dissonance occurs in the eighth and final verse of “Oh My Darling Don't Cry" (Run the Jewels, 2014), excerpted in Example 11. In this passage, Killer Mike rhymes 'game', '“caine', '(a)gain', and '(in)sane' across a variety of metric positions. While Killer Mike begins this verse on the hyperdownbeat of the beat's main twomeasure loop (as shown in the example), his single-syllable rhymes - which punctuate the metric units of his flow - create groupings of three and four eighth notes, meaning that their grouping boundaries rarely fall on the same beat. Thus, Killer Mike's technique of combining strings of triplets in varying lengths enables him to interact with the beat layer in such a way that creates a slight metric tension between the two layers, all while using a limited rhythmic palette of sixteenth-note triplets and eighth notes and combining forward-propelling triplet flow with punctuating rhymed syllables.

In his song 'Best Friend' (2015), Young Thug raps most of the first verse in triplet flow, and as Example 12 shows, the beginnings of some of his lines of lyrics occur one quarter note earlier than the beginning of the harmonic loop that comprises the beat layer. Contrary to the technique used by G-Eazy in 'Me Myself \& I' - where a line of lyrics with a delayed beginning still ended in concordance with the metrical structure of the beat-here Young Thug continues rapping over the subsequent downbeat of the beat layer, making the displacement between flow and beat more audible. 


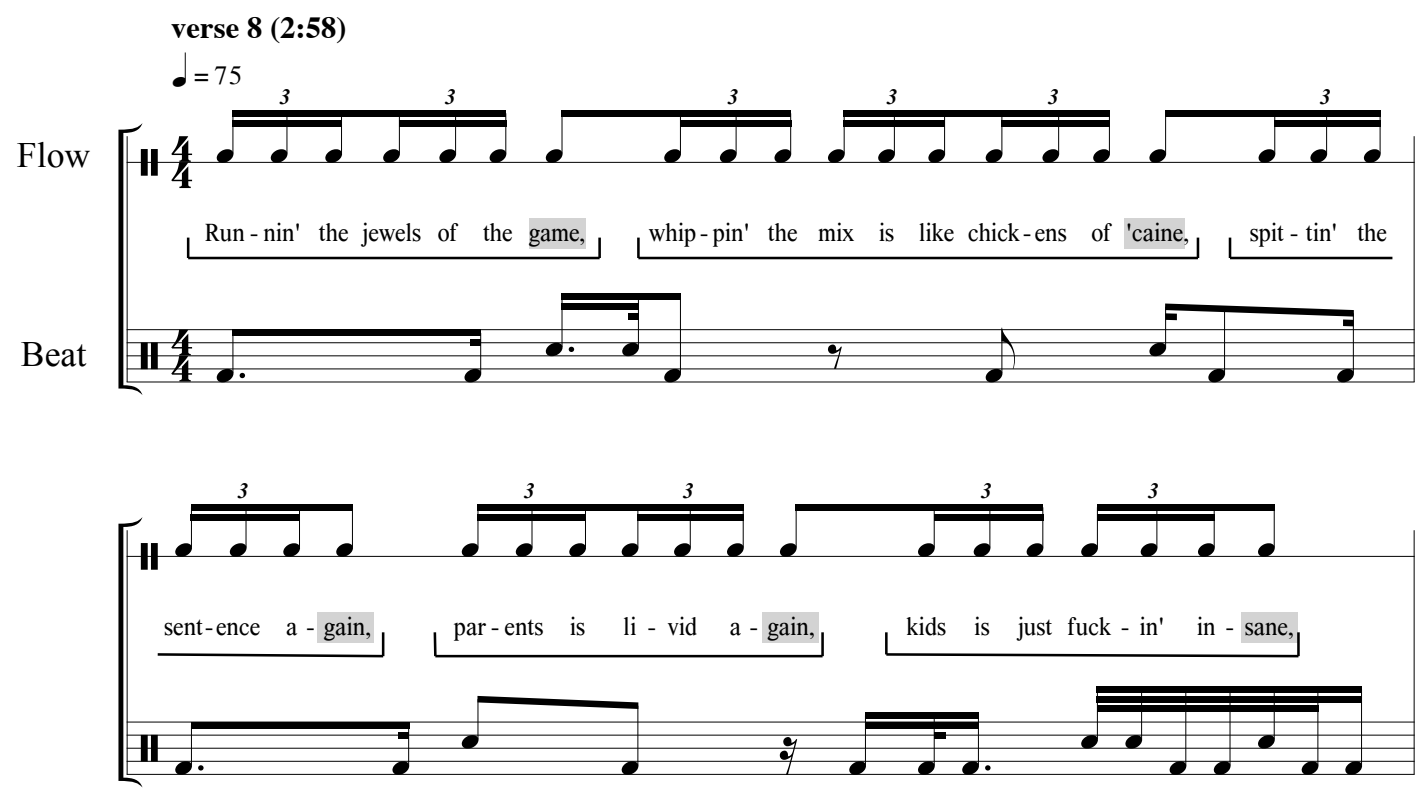

Example 11: 'Oh My Darling Don't Cry' (Run the Jewels, 2014). The beat layer is represented by the drum pattern. As shown with the brackets and highlighted rhyme syllables, the flow layer's grouping boundaries occur in varying metric positions.

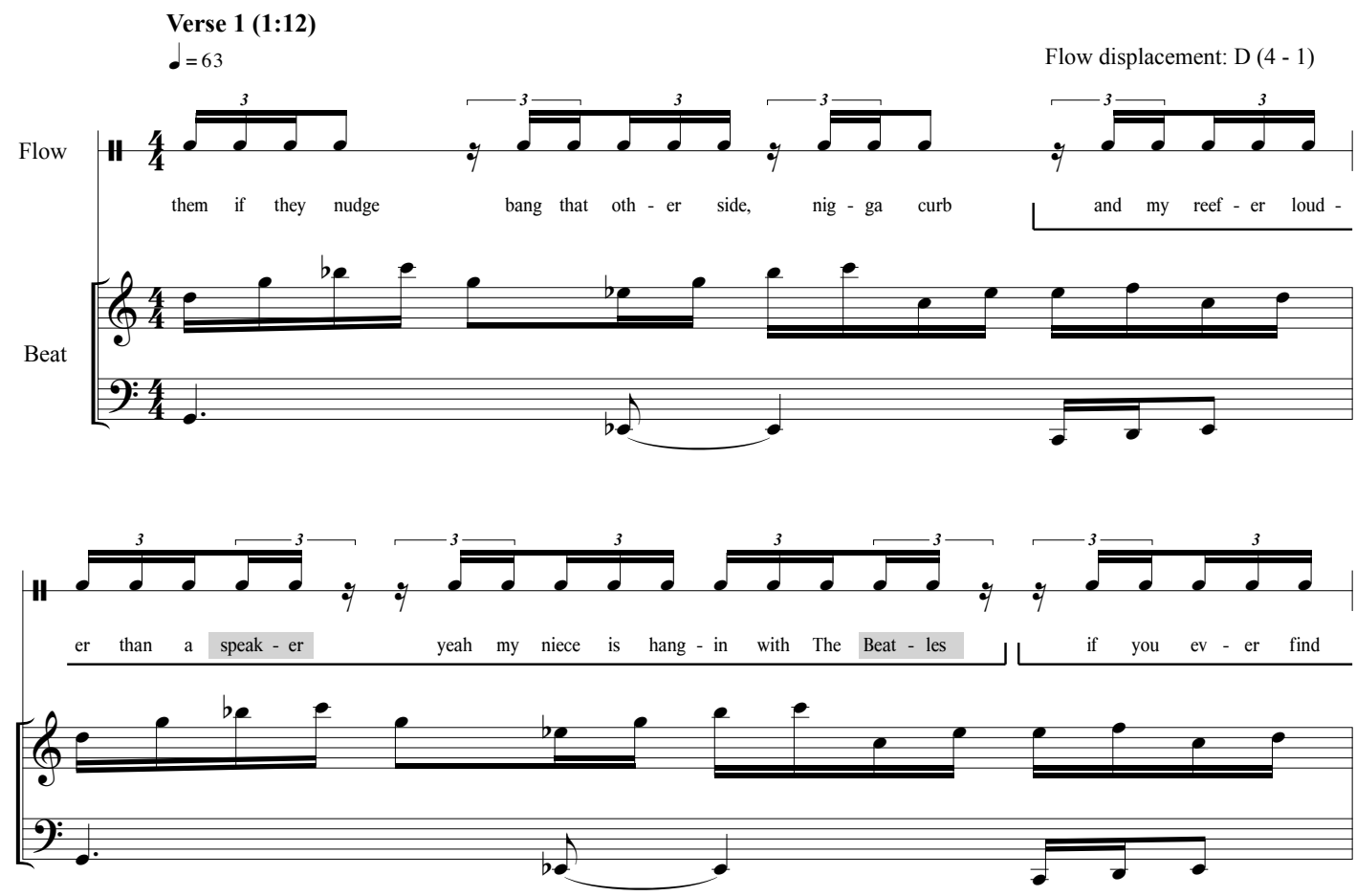

Example 12: 'Best Friend' (Young Thug, 2015). The beat layer here includes the bass line and plucked-string melody. As the brackets under the lyrics show, the flow layer is displaced from the beat layer by D(4-1), meaning that each layer exhibits groups of four quarter notes, and the flow layer's groups begin one quarter note earlier than those of the beat layer. 
Revisiting a song discussed earlier, the second verse of Kendrick Lamar's 'Swimming Pools' (Example 3b) demonstrates a concise example of how triplet flow-with the aid of its signature characteristics - can sculpt the form of a song section. Lyrically, the verse divides neatly in two. During the first half (beginning at 1:30, not shown in the example), Lamar's conscience offers stern advice regarding his excessive drinking habits, while during the second half (beginning at 1:42, partially shown in Example 3b), Lamar offers his own reflections on this advice. The phrases constituting the first half of the verse are displaced metrically from the beat, and they all utilize multi-syllable rhymes. The clarity of formal organization here corresponds to the clarity of the conscience's message: curb your excessive drinking habits or face the consequences. The phrases constituting the second half of the verse (partially shown in Example $3 \mathrm{~b}$ ) use a combination of single- and multi-syllable rhymes whose varied metric locations create a grouping dissonance with the beat, as shown with brackets in the transcription. The lyrics parallel this increase of complexity, as now Lamar grapples with acknowledging binge drinking's negative effects while also being aware of alcohol's enabling characteristics. Thus, the formal, rhythmic, and lyrical trajectory of this verse tends to follow a unified course from simplicity to complexity, building suspense and energy that carries forward into the following hook (1:56).

\section{Mixed, phrasal, and total triplet flow}

Most songs in the corpus feature triplet flow at the phrase level (phrasal triplet flow). Slightly less prevalent are songs that use total triplet flow at the level of the verse or hook. Rarest are songs that either only use triplet flow at the sub-phrase level (mixed triplet flow), or those that use it throughout the entire song (total triplet flow). Mixed and phrasal triplet flows describe situations where triplets are interspersed with other (usually duple- or quadruple-divided) rhythms, either at the sub-phrase or phrase level, respectively. Stark contrast often characterizes this interspersing: the duple rhythms are usually freer and more varied in construction, while the triplet flow proceeds, simply, in a string of triplets. The contrast, depending on the context, can evoke a variety of effects. The listener's sense of metre might be destabilized, or the motional energy of the musical passage might be affected. I will now proceed by dissecting an example of mixed triplet flow and focusing on its effects on the listener, followed by a similar procedure for examples of phrasal and total triplet flow.

Long Beach rapper Vince Staples uses mixed triplet flow in his 2015 single 'Senorita'. This song's main hook comes from Atlanta artist Future's single 'Covered N Money'. While most of the triplets in this track occur during the hook, Staples raps much of the first verse in mixed triplet flow, as suggested by the excerpt transcribed in Example 13. Staples rhymes certain syllables more than twice, varies the metric location of these rhymes, and therefore also varies the alignment of lines with the underlying metric structure of the beat. 


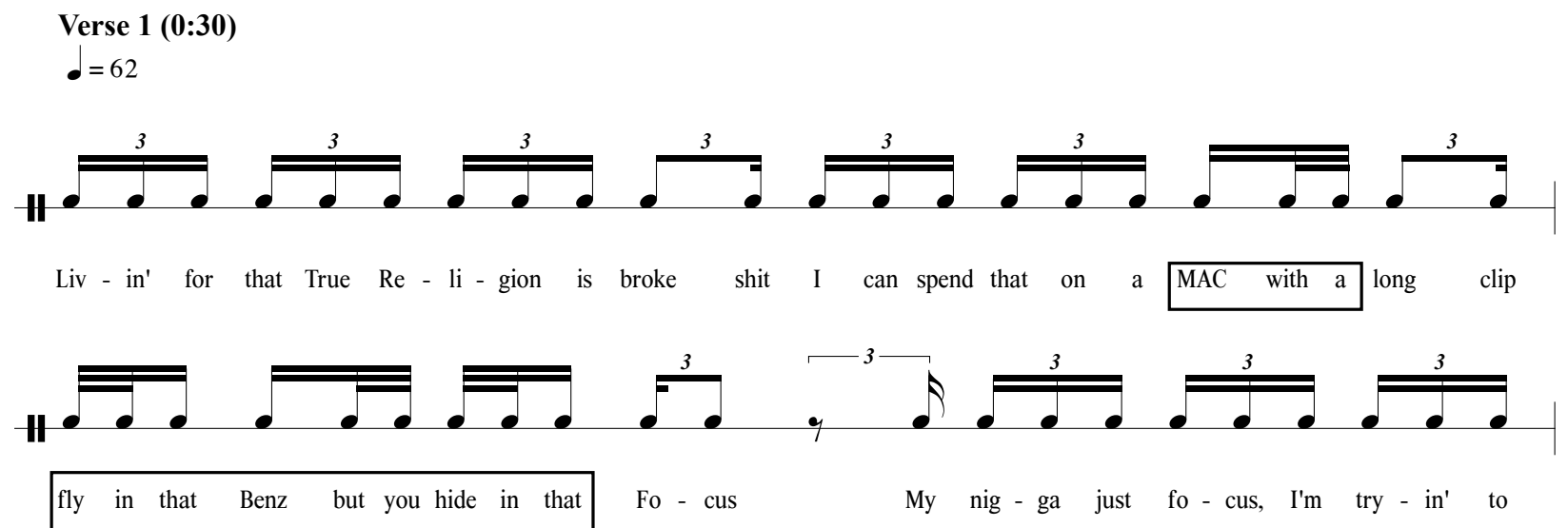

Example 13: 'Senorita' (Vince Staples, 2015). The boxed lyrics indicate where, amid triplet flow, Staples raps syllables closer to a duple/quadruple rhythmic division. In several of these instances, his rhythms are noticeably inexact; that is, he inflects his rhythmic delivery with microtiming variations. While this technique is ubiquitous in hip-hop music, it is especially salient in this example, as it contrasts sharply with the regularity of the triplet flow in the hook section of this song.

In a nod to speech-effusive rapping, Staples frequently alters triplets to match what occurs in the natural stresses of the text. For instance: instead of rapping in triplets for the words 'fly in that Benz but you hid in that', Staples raps the words closer to the way they might be spoken naturally, rather than being tripletized..$^{38}$ Thus, in using mixed triplet flow, Staples exploits the rhythmic tension inherent between natural speech rhythm and triplet flow. This example is, however, not that simple. The transcription does not always exactly reflect how Staples raps; his microtemporal variations, especially on the duple rhythms, mean that his flow occasionally lies somewhere in between duple and triple. ${ }^{39}$ Throughout this verse, the expressive effect of Staples' flow varies. On the one hand, the frequent interjection of duple rhythms has a disorienting effect on the listener's perception of regularity in the flow. On the other hand, these approximations allow Staples to sound calm and in control, as though his mixture of triplets and duplets is merely a by-product of his lyrical delivery.

I now turn to two examples of phrasal triplet flow wherein the orientation of triple and duple rhythm within a verse imposes contrasting effects on the motional energy created by the flow. In each of the following excerpts, the $\mathrm{MC}$ raps in a mixed duple-rhythm flow before switching to a constant string of equally-spaced triplets. In 'Oh My Darling Don't Cry' (Run the Jewels, 2014), Killer Mike raps the fourth verse as transcribed in Example 14. He switches to triplet flow on the lyric "blowin" and, while the earlier part of this passage includes a mixture of intricately divided duple rhythms, the incessant regularity of the triplets allows Killer Mike to

\footnotetext{
${ }^{38}$ I take precedent for making these assumptions about natural speech rhythms from Harald Krebs' work on declamation in Schumann Lieder (2014). Specifically, as English is a stress-timed language (like the German language studied in Krebs' work), stressed syllables are typically spoken with different durations than unstressed syllables. Consequently, when a stress-timed language is spoken (in this case rapped) in consistently equal rhythmic values - in this case triplets - the normal durations for stressed syllables are suppressed.

${ }^{39}$ Kyle Adams (2015) highlights the problems associated with transcribing flow using Western notation, namely this system's inability to represent the subtle rhythmic fluctuations inherent in most MCs' flow. Danielsen (2010) has made a significant foray into this research area in the more general domain of Afro-American musics, and Ohriner (2017) has done some of the most detailed work with microtiming concerning hip-hop flow specifically.
} 
slowly increase the perceived motional energy of this passage, driving toward the caesura following the word 'whiskey'.

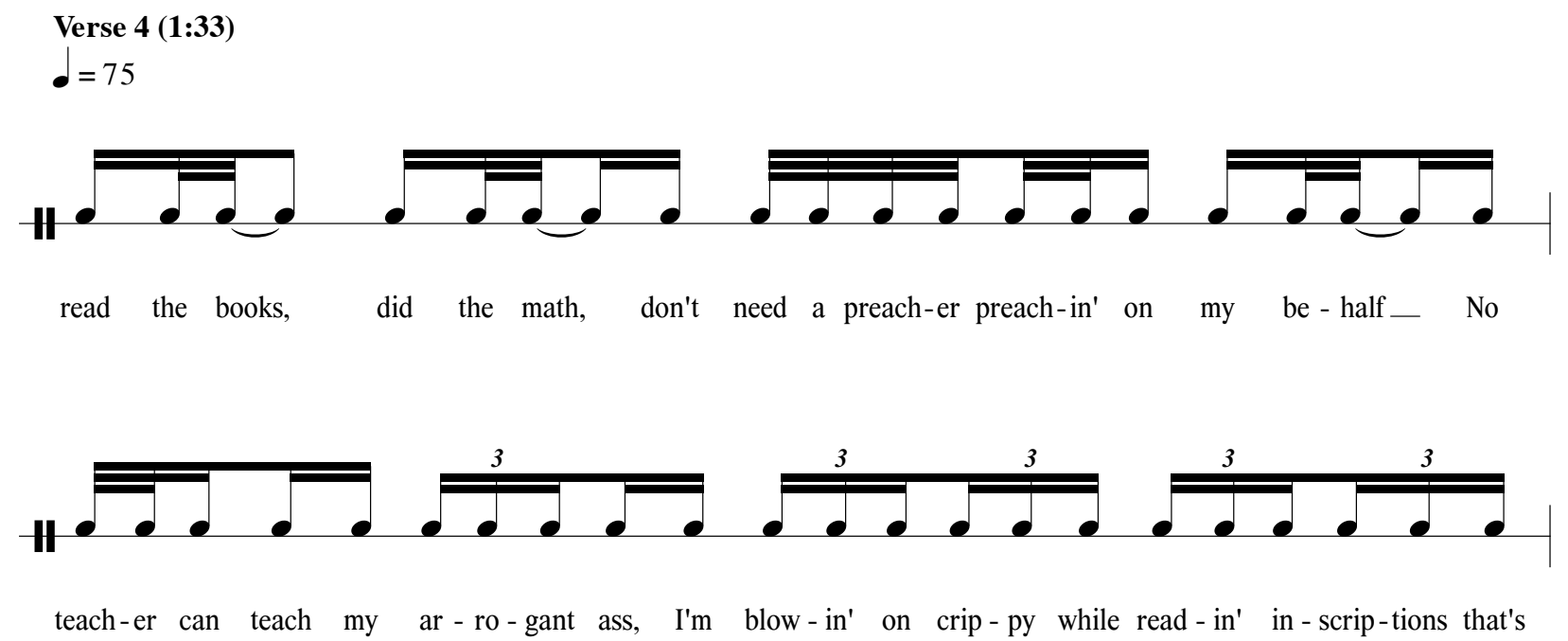

Example 14: 'Oh My Darling Don't Cry' (Run the Jewels, 2014).

While the syllabic density per measure thus increases only slightly once Killer Mike begins rapping in triplets, the motional energy of the passage increases dramatically, mainly due to the incessant rhythmic regularity of the triplet flow. In 'Ooh Kill'em' (Meek Mill, 2014), the triplet flow creates the opposite effect: a decrease or dissipation of motional energy. Shown in Example 15, Meek Mill progresses from an intricate mixture of duple rhythmic values to a steady stream of triplets on the lyric 'I grew up'; any sense of motional energy generated by the duple section is momentarily suspended through the triplet flow, which planes over the beat layer. Triplet flow can thus generate contrasting changes in the motional energy trajectory of one or several phrases of lyrics.

Verse $1(0: 32)$

$\downarrow=67$

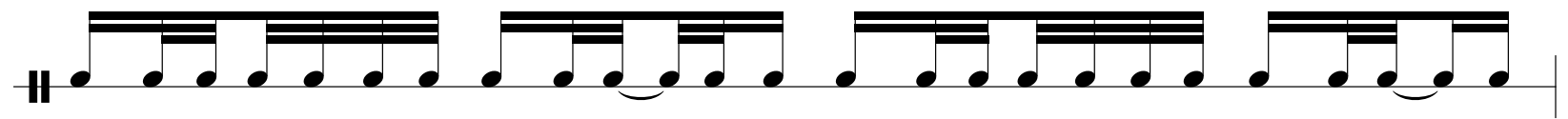

few Phil-ly nig-gas that be shoot - in' shit_ I'm like Dre, wish I had my nig-ga Snupe for this_ Oh,

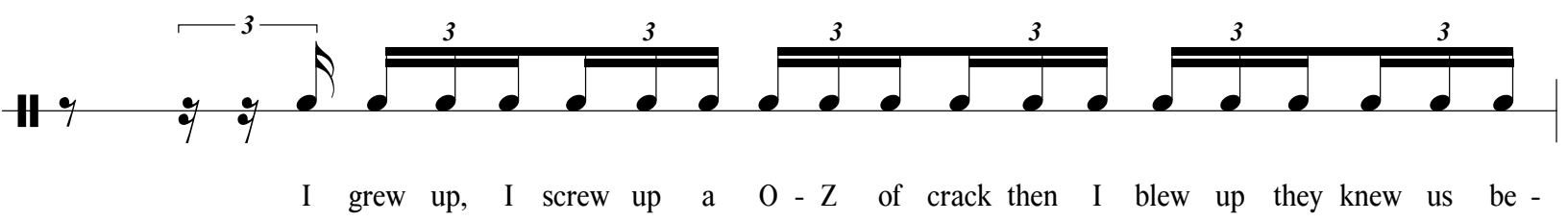

Example 15: 'Ooh Kill'em' (Meek Mill, 2014). 
Finally, while total triplet flow examples are comparatively rare, the rhythmic and phrasal profiles they can assume are markedly varied, as the remaining examples in this paper will show. The first verse (0:44) of 'Paradise (Extended)' (Big Sean, 2015) features triplet flow in its most elemental form: a largely uninterrupted string of triplet figures stretching throughout an entire verse. Big Sean's decision not to punctuate lines of tripletized lyrics with rhythmic caesuras has the potential to evoke more of a flowing stream of consciousness rather than an organized narration or assemblage of related subject matter. As Example 16 shows, however, the rhyming scheme organizes quite tightly to the beat's faintly established metrical structure. A tight rhyme scheme coupled with lack of caesuras has an especially jarring effect on the listener through the first two measures, as the drums and saxophone have momentarily dropped out of the beat, giving the passage a timeless, suspended feel. Since Big Sean exploits the metric tension between lexical and metric accents in the third and fourth measures (as the highlighted syllables show), the listener is left with few obvious markers of metre by the time the drums and saxophone return (at 0:59) to jarringly re-impose metrical order to the verse.

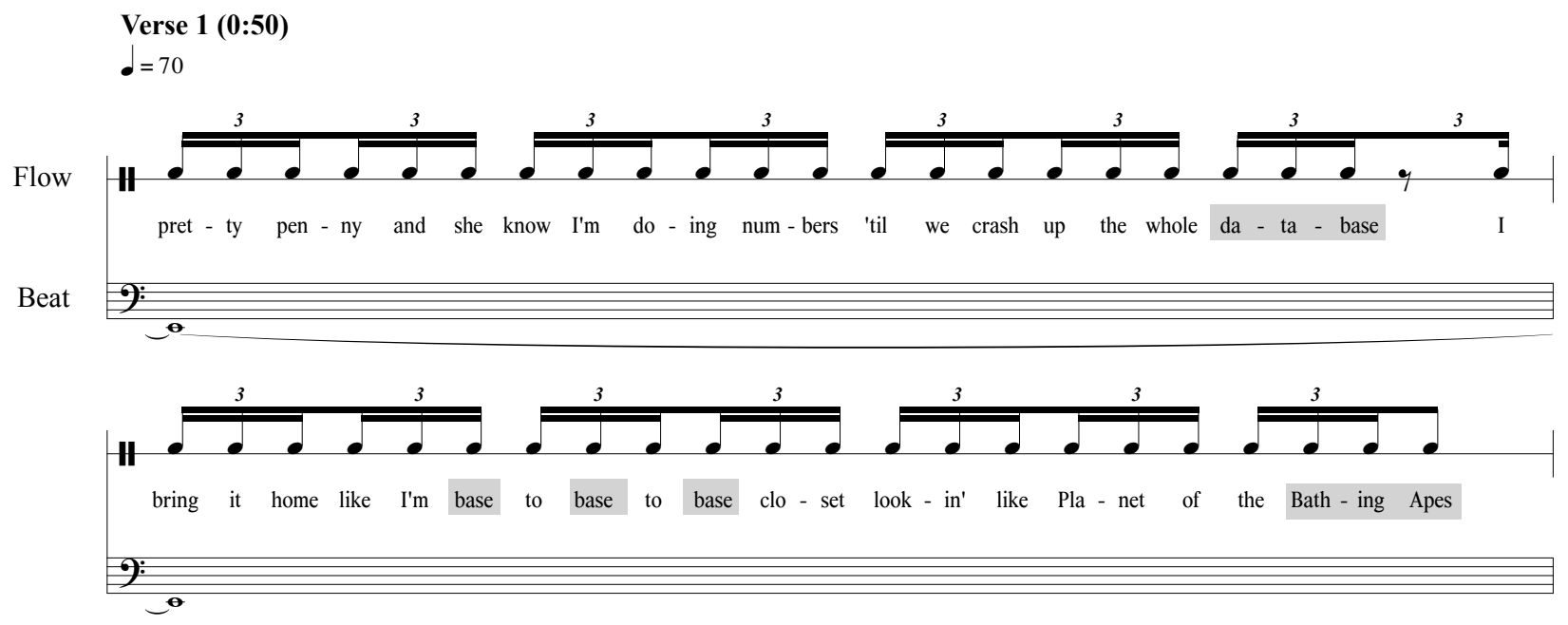

Example 16: 'Paradise' (Big Sean, 2015). The beat layer is first represented by the drone bass, followed by baritone sax sample and drums in $m .5$.

\section{Two analyses}

Dark Sky (Skyscrapers)

Though it was his third studio release, Detroit-based MC Big Sean's 2015 album Dark Sky Paradise was his first to reach number one on the Billboard Hot 200 chart. The opening track, 'Dark Sky (Skyscrapers)', sets a serious and sombre tone that pervades much of the album, and exemplifies Big Sean's nuanced triplet flow, which he uses in the second verse of the song (beginning at 2:02). With a tempo of $71 \mathrm{bpm}$, the triplet flow in 'Dark Sky (Skyscrapers)' demands of Big Sean a considerable amount of speed and agility; merely to 'get through' the verse at this tempo requires heightened technical skill and virtuosity. Markers of creativity are also present: Big Sean evokes all three of Krims' flow styles in the context of a single verse. In one sense, his flow is very simplistic: the triplet rhythms themselves are incessantly regular, almost percussion-effusive at times, and are imbued with rhythmic precision. In another sense, 
Big Sean's sing-song delivery and clearly demarcated vocal phrases are emblematic of sung style. Yet his flow also embodies speech-effusive style: he rarely strays from stressing words according to their lexical stress points, even when these do not line up with metrical accents. To elaborate on this last point, Big Sean's flow in this verse exploits the tension between lexical stresses of lyrics and metric structure implied by the metre of the beat-largely absent in this verse, but maintaining a skeletal presence through a sparse bass line texture.

Based on the rhyme structure, the verse divides into three units of equal length. Three rhyme chains are used; one per unit. The first unit (2:02-2:15) bears all the stylistic markers of triplet flow discussed in the previous section. A delayed vocal onset begins the verse (2:02), the rhyme and caesura patterns are irregularly spaced, and the rhymes are multisyllabic. As shown in Example 17a, Big Sean rhymes 'speak to me' with 'Z Z Z's', and 'peat-ed-ly', and continues using tri-syllabic rhymes several more times (not shown in example). The metric position of these rhymes leads to the grouping dissonance with the beat shown by the brackets in the example: the groups of flow here run in lengths of 3, 5, 3, 5, 3, 4, and 8 eighth notes respectively (though only the first four are shown in the example). The delayed onset of one eighth note contributes to the effect of the grouping dissonance. As the transcription in Example 17b hypothesizes, if Big Sean were to have begun in sync with the beginning of the measure, the rhymes would occur at more predictable metric locations. ${ }^{40}$ In this hypothetical situation, instead of spilling over each bar line implied by the beat layer, the rhymes and the phrases they support line up with the measures. More often than not, rhymes that end lines of hip-hop lyrics fall at or toward the metrical end of a measure, hypermeasure, or internal division of a measure. Thus, by displacing the first phrase by a quarter note, Big Sean's rhyme placement challenges this convention, and disorients the listener's sense of metre. ${ }^{41}$

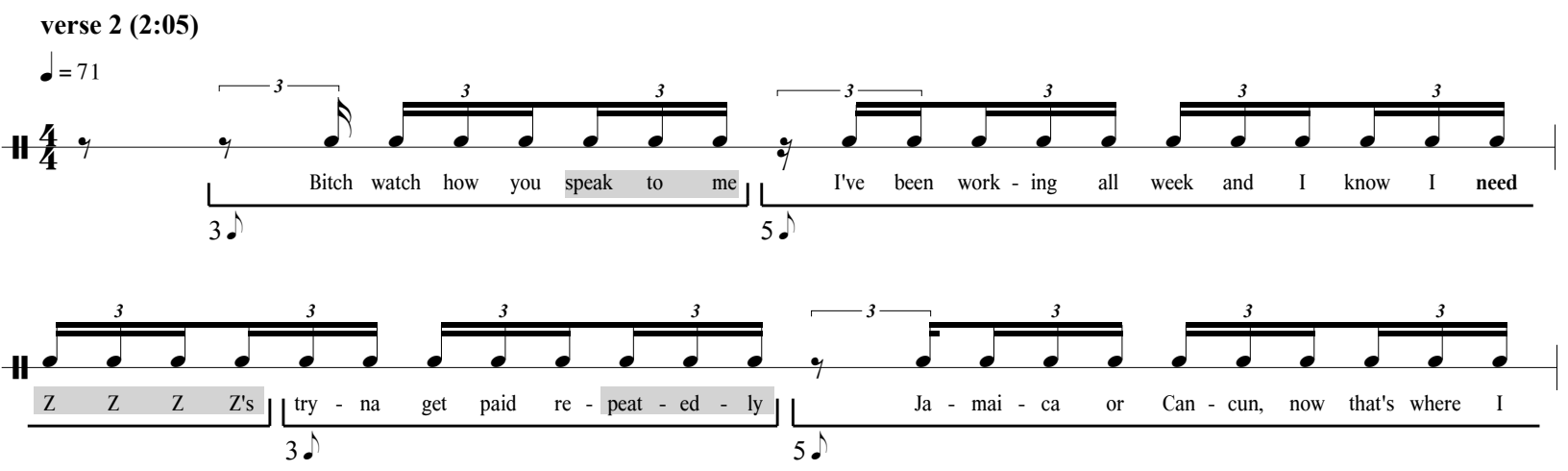

Example 17a: first part of verse 2, 'Dark Sky (Skyscrapers)'. Phrase lengths are measured in eighth notes, as shown below each bracket. The final bracket is open-ended in the transcription because it continues over into the next measure.

\footnotetext{
${ }^{40}$ Condit-Schultz (2016) found that rhyming syllables tend to occur later in musical measures, or at the ends of vocal phrases that line up with the beat's metre.

${ }^{41}$ Here I follow the lead of Adams (2009), who observes a similar clouding of metre-as-heard in Madvillain's 'All Caps' (2004). Since hip-hop music is a non-notated genre, even when scholarship relies on notated scores for explanation, it makes more sense to discuss metre always in the context of how it is heard or felt, rather than how it is notated.
} 


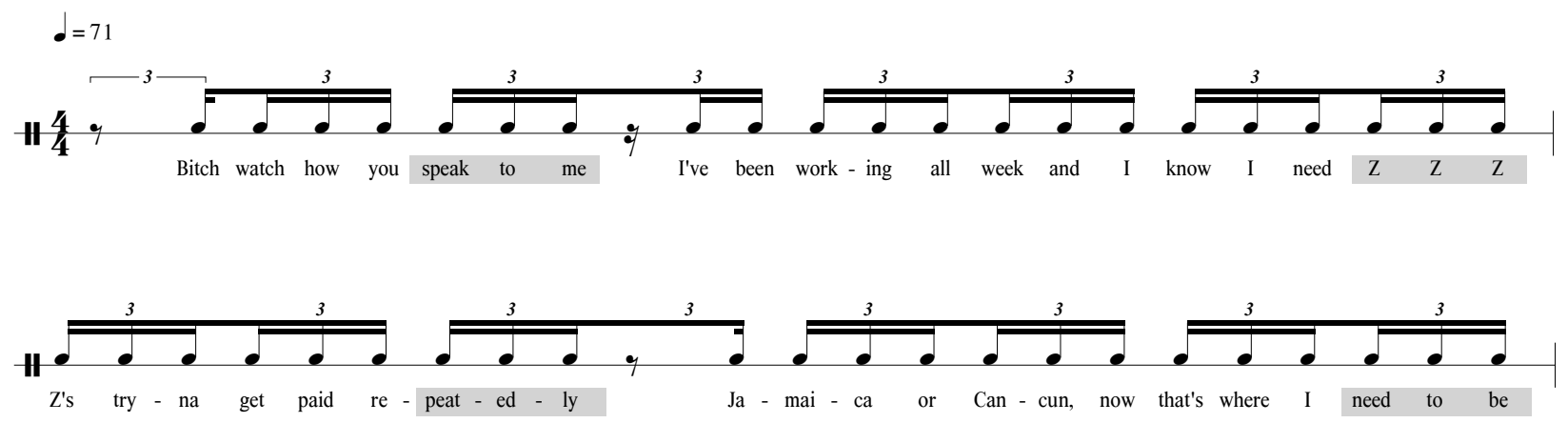

Example 17b: first part of verse 2, 'Dark Sky (Skyscrapers)', with the vocals shifted backwards by one eighth note. This shift puts the rhyming syllables in positions that eliminate part of the grouping dissonance detailed in Example 18a. For instance, the second vocal phrase now concludes in sync with the notated measure, which itself is notated according to the metric structure of the beat.

Despite the metric complexity created through delayed vocal onset and varying group length, the first three measures of this verse are relatively concordant when we consider how natural they sound to the ear. The prosodic stresses of the lyrics tend to fall in convincing metric locations. For example, a plausible way to utter the first sentence of the verse would be to stress the word 'speak', as in 'bitch watch how you speak to me'. Indeed, the lyric 'speak' occurs on a downbeat of a triplet, and listening to the recording reveals that Big Sean raises his vocal pitch slightly on this lyric to emphasize it. A similar process occurs in the lyric 'try-na get paid repeat-ed-ly', where the syllable 'peat' is stressed, falls on a downbeat, and perhaps logically carries prosodic stress of this sentence. The interaction between prosodic, lexical, and metric accents gets thrown into relief in the passage beginning at 2:12. Big Sean performs the phrase with a variety of accented and unaccented syllables. On multi-syllable words like 'think-ing' and 'be-com-ing', his performed accents line up with the lexical stresses of the words (bolded here).

The balance between lexical or prosodic stresses and metric accents becomes more complicated in the second half of this passage, beginning at the lyric 'so I'. Here again the prosodic stresses occur when we might expect them to if the lyrics were spoken, out of musical context. These prosodic stresses, however, do not line up with any eighth-note downbeats in the triplet flow. As a result, this phrase substantially distorts the sense of metre-as-heard in the verse thus far. While the passage beginning at 2:02 challenges the metre at the quarter-note tactus level - strings of triplets of varying lengths create grouping dissonance - the prosodic accents in the passage beginning at 2:12 challenge the metre even further: while the first accents on the syllables 'I've', 'think', 'bout', and 'com' create an eighth-note triplet, the accents on 'I', 'murk', 'nig', 'one', and 'one' distract the listener's ear from the underlying triplets. As a result, Big Sean nearly completely obfuscates the metre-as-heard until reorienting the listener with the lyrics 'I talk that real shit' at 2:17.

Grouping dissonances, syncopated prosodic stresses, and multi-syllable rhymes continue to characterize this verse until its end. The dialogue between the simplicity and rhythmic balance of triplets occupies the constant foreground of this verse, and the complex scheme of punctuation, accent, and rhyme. This dialogue between rhythm, accent (including changes in vocal tessitura to effect accent), and punctuation is essential to the construction of rhetoric in an MC's flow. By choosing a trio of syllables to repeatedly rhyme, and by carefully placing 
caesuras, Big Sean adds coherence to the evolving subject matter of this verse. Consider, for example, the passage beginning at 2:17. Big Sean first speaks of representing his home city of Detroit and being praised for speaking from the heart and concludes the unit by relaying advice given to him from his father. These disparate topics are woven together foremost by the rhyme scheme, where the same three syllables are rhymed between $2: 17$ and 2:30. The lyrics flow, without a caesura, from one topic to the next: 'treat-ing it like it's the mo-ther-ship // was talking to my dad though on some ot-her shit'. ${ }^{42}$ Finally, in two moments where the subject matter or tone shifts rather abruptly, so does Big Sean's accent structure. This can be heard in the abrupt turn to Big Sean's sarcastic comments on racial profiling in police work (2:13), and again in the culmination of his self-reflection $(2: 38)$. Though these constitute but a handful of observations on how an MC can harness rhythm, articulation, and accent for rhetorical purposes, they show specifically how such practices can be utilized in the context of triplet flow.

\section{Panda}

As a final analytical excursion, I return to the 2015 sleeper hit 'Panda', notable for the presence of total triplet flow throughout the whole song. At first listen, 'Panda" may not sound altogether intriguing for analysis - the lyrics are repetitive, in some instances contain nonsequiturs, and the constant airplay the song received has led to some derision among critics and fans alike - but with closer scrutiny, several features of Desiigner's flow warrant analytical discussion. ${ }^{43}$ The lyrics follow a nearly palindromic form, with two pairs of hooks bookending a longer central verse. While the flow in the chorus follows a repeated rhythmic pattern, the central verse (1:46-2:38) departs from this pattern in a variety of ways. The central verse divides further into four units of equal lengths (beginning at 1:46, 1:59,2:12, and 2:25, respectively), according to the aurally-salient trajectories of syllabic density in the flow.

Each unit undergoes an elaboration or intensification process wherein the rhythmic and prosodic structure of the flow in the first measure of each unit becomes modified across the latter three measures. In the first unit (partially excerpted in Example 18), the rhyming and rhythmic structures across the first two lines of lyrics are largely consistent. The syllables 'At-lan-ta', 'Fan-ta', 'Scam-mers', and 'De-siign-er' are rhymed on the eighth-note offbeats of beats two and four. (Desiigner pronounces his own moniker so as to rhyme in this sequence, making it sound more like 'De-zan-na', converting 'scammers' and 'Desiigner' from a slant-rhymed pair to a perfect-rhymed pair. ${ }^{44}$ ) Interpolating these multi-syllable rhymes are the words 'broads' and 'cards' (pronounced 'cawds'), as well as the syllable sets 'lean and shit' and 'Ver-sa-ce shit'. These syllable sets form the model for subsequent rhymes later in the unit, but the metric placement of these rhymes causes the flow phrases to misalign with the beat, similar to what was seen in "Best Friend" (Example 12).

\footnotetext{
42 Big Sean weaves these topics together with wordplay, following 'mothership' with 'dad'.

${ }^{43}$ Friedman (2016) discusses the reasons for derision toward Desiigner and his success, focusing mainly on how the Brooklyn rapper has capitalized on Atlanta-based Future's signature sound. Lil' Donald, an MC on Future's label Freebandz, released a Desiigner diss track called 'Fuck Panda' in May 2016, using the same beat as 'Panda'.

${ }^{44}$ Slant rhymes refer to rhymed pairs where the final consonant rhymes, but the final vowel does not. Bradley (2009, 48) uses the example of 'all' and 'bowl' for explaining slant rhymes.
} 


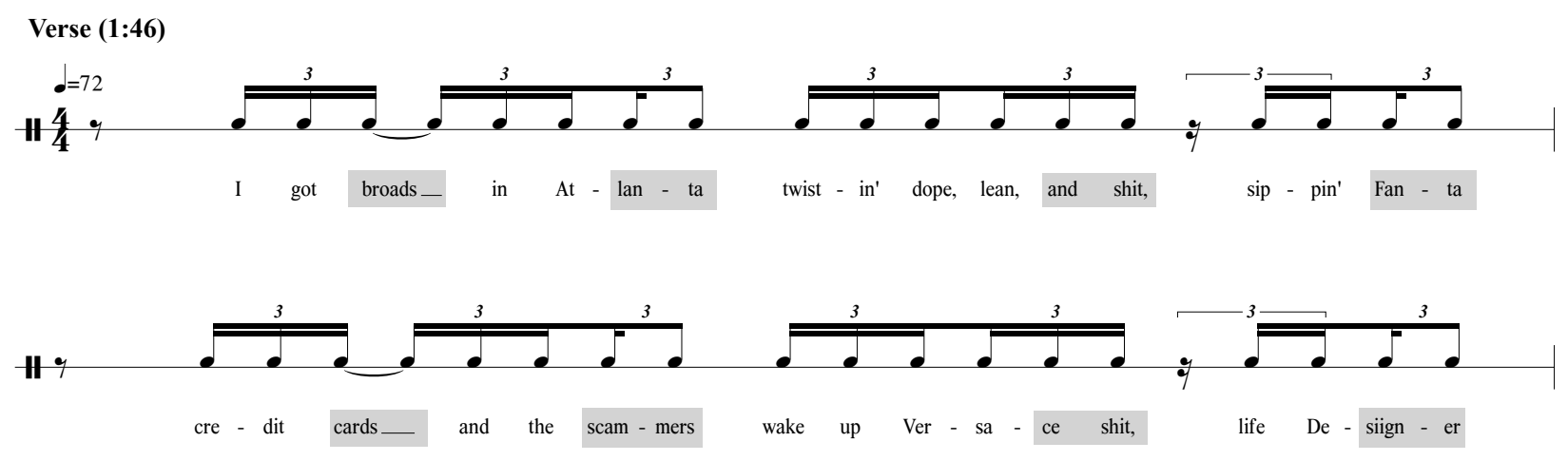

Example 18: excerpt of the first part of the verse in 'Panda' (Desiigner, 2015).

The fourth unit (2:25-2:38) is the most striking in terms of rhyming structure and metric interplay between the flow and beat, uniting two of the stylistic features discussed in the last section: delayed vocal entries with grouping dissonances. The flow follows a displaced tresillo pattern: the phrases are four quarter notes (one measure) long, and follow a $3+3+2$ pattern (values in eighth notes), such as over the lyrics 'I got broads yeah I get it' (3), 'I get cards yeah I shit-ted' (3), 'This how I live it' (2). Each tresillo pattern begins one eighth note later than the beat. To effectuate this displacement, Desiigner adds a placeholder lyric in 'get it' at the beginning of the unit, in that it does not join syntactically to the lyrics it follows or precedes, but functions metrically as a rhyme with three measures that follow it. The rhythmic pattern used for the three-eighth-note long portions of the tresillo pattern comes from the opening motive of the verse on the lyrics 'I got broads from At-lan-ta'. In this way, the fourth unit functions as an elaborated recurrence of the opening material.

\section{Conclusion}

Through this article I have endeavoured to focus on triplet flow by examining its development and recent popularity, its stylistic markers, its ostensible simplicity yet underlying complexity, and its potential as a rhythmic template for creativity, virtuosity, and rhetoric. To begin, I defined triplet flow via the three main formal contexts in which it occurs: at the subphrase (mixed triplet flow), phrase (phrasal triplet flow), and formal unit or song (total triplet flow) levels. I then situated the characteristics of triplet flow within Adam Krims' stylistic categories of flow, which includes speech-effusive, percussion-effusive, and sung styles. Using Krims' system to show that triplet flow bears markers of his styles demonstrates that triplet flow acts as more than a novel tool MCs can use to diversify their flow; it has the potential to function as a versatile rhythmic base supporting a wide range of idiosyncratic flows MCs might use. I then analysed several early examples of triplet flow in order to highlight the stylistic blueprints of this flow. Further work could be done to show how these early examples influenced, inspired, or provided source material for later triplet flow, but this work should acknowledge the danger of assuming well-defined stylistic relationships between artists and songs without supporting ethnographic research. For this reason, I have avoided speculation on precisely how triplet flow evolved from its earliest forms in songs by Public Enemy and others, instead endeavouring to illuminate the diversity in triplet flow that existed already in those early years.

With the aid of a fifty-song mini-corpus, I then enumerated and unpacked four stylistic markers of modern triplet flow: multi-syllable rhymes, delayed vocal entries, grouping 
dissonance, and the somewhat narrow song tempo range of 60-75 bpm. I used songs by G-Eazy, Big Sean, Run the Jewels, Meek Mill, Vince Staples, and Young Thug to exemplify these markers and provide examples of phrasal (more common) and total (less common) triplet flows. Utilising this corpus further, research could be undertaken to evaluate how unique to triplet flow these markers are. I suspect that certain markers such as grouping dissonance and delayed vocal entries are more universal than this corpus might suggest, but that the distribution of song tempos and prevalence of multi-syllable rhymes might correlate more strongly with songs using triplet flow.

In analysing 'Dark Sky (Skyscrapers)' and 'Panda' in greater detail, I focused on longer and more nuanced examples of triplet flow. In 'Dark Sky (Skyscrapers)' I discussed how Big Sean harnesses triplet flow to both inform and be informed by the prosodic and lexical stresses of his lyrics. In 'Panda' I focused on how Desiigner begins with a rhythmic motive in triplets and elaborates on it, shifting accent location, increasing rhythmic density, and displacing phrase/group boundaries. Here and elsewhere in the article I began to ruminate on how these techniques shape the rhetoric of the lyrics; more work in this direction could (and should) be done in order to cast into increased relief the relationship between lyrics, flow, and beat in hiphop music. In addition, further research toward developing analytical methods that account for expressive microtiming in flow would help us better understand the subtleties of relationship between natural speech rhythms and rhythmicized triplet flow.

Through these two longer analyses and the shorter ones that preceded them, I have shown how, in triplet flow, a variety of metric, accentual, and phrasal techniques can be superimposed onto a rhythmic surface that is, on its own, often quite simplistic. The nuanced metric placement of rhyming syllables, the alternation of single- and multi-syllable rhymes, the displaced vocal onsets, grouping dissonances between flow and beat, and the possibility of mixture between duple and triple rhythms combine to give the most compelling - though often simple on the rhythmic surface - occurrences of triplet flow astounding complexity and variety. I have also attempted to show that part of triplet flow's appeal to MCs and consumers of hip-hop music alike lies in the complex - often tension filled - interaction between the lexical and prosodic stresses inherent in the English language and the triplet rhythms themselves. ${ }^{45}$ To be sure, many of these techniques are used in duple-based flows as well. But their presence in the increasing repertory of triplet flow songs further illuminates their role as markers of virtuosity, creativity, and rhetoric, as well as triplet flow's ability to showcase these markers.

Whatever its appeal may be, triplet flow appears to be here to stay. A survey of recent releases by Young Thug (Beautiful Thugger Girls, 2017), Migos (Culture II, 2018), Future (Future, 2017 \& HNDRXX, 2017), Big Sean (I Decided, 2017), Kendrick Lamar (DAMN, 2017 $\&$ Black Panther, 2018), and Cardi B. (Invasion of Privacy, 2018) suggests that triplet flow has become part of these artists' toolkits. Childish Gambino's use of it along with a dark-sounding trap beat in 'This is America' (2018) helps illustrate the narrative irony and contrast embodied in that song's lyrics. Furthermore, triplet flow-influenced singing has begun to make its way into mainstream popular music, as Example 19 details for the pre-chorus of Ariana Grande's 'God is a Woman' (2018).

\footnotetext{
${ }^{45}$ As a durational-stress language, spoken English relies on varying syllabic durations to generate proper context and meaning. The regularity of triplets challenges this paradigm of English, as the foregoing analytical work has demonstrated.
} 


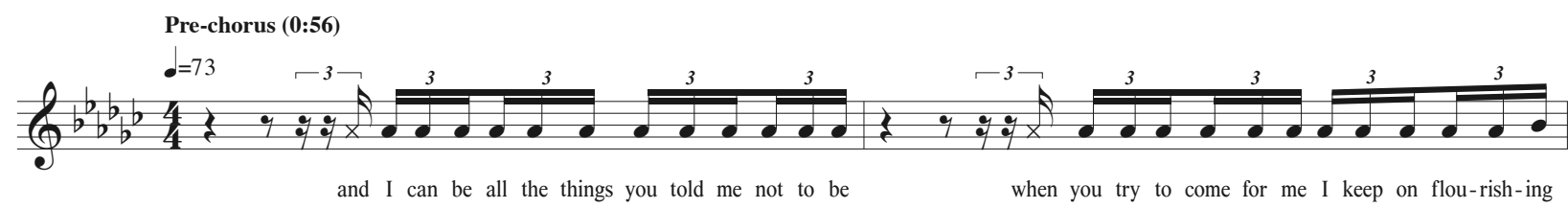

Example 19: pre-chorus from "God Is a Woman" (Ariana Grande, 2018). X-shaped note heads represent unpitched lyrics in Grande's performance.

Perhaps triplet flow has asserted itself as a popular style alongside more established styles of flow; not overused, but often present in some quantity. I have suggested that modern triplet flow comes from Southern hip-hop music, especially through its popularization by Three 6 Mafia and current use by Atlanta trap rappers like Young Thug, Migos, and Future. If triplet flow was originally a Southern phenomenon, it now permeates every region of the North American hip-hop landscape, including Francophone hip hop coming out of Quebec. As discussed earlier, recent writings suggest we are currently in a post-regional era of hip-hop music, where subtle stylistic variations between geographic regions have evaporated, largely due to the internet's presence in and influence over the commercial music industry. Triplet flow, therefore, functions as prime sonic evidence that stylistic traits developed in the South now dominate the hip-hop genre at large. If good things do come in threes, hip-hop music has arguably found something good in triplet flow. 


\section{References}

Adams, K. 2008. 'Aspects of the Text/Music Relationship in Rap', Music Theory Online, 14(2)

- 2009. 'On the Metrical Techniques of Flow in Rap Music', Music Theory Online, 15(5)

- 2015. 'The Musical Analysis of Hip-Hop', in The Cambridge Companion to Hip-Hop, ed. J. Williams (Cambridge), pp. 118-134

Biamonte, N. 2014. 'Formal Functions of Metric Dissonance in Rock Music', Music Theory Online, 20(2)

Billboard Music. 2018. Desiigner Chart History (Accessed Mar 6, 2018) https://www.billboard.com/music/desiigner/chart-history/rap-streamingsongs/song/963804

Bradley, A. 2009. Book of Rhymes: the Poetics of Hip Hop. New York: Basic Civitas.

Butterfield, M. 2006. 'The Power of Anacrusis: Engendered Feeling in Groove-Based Musics', Music Theory Online, 12(4)

—. 2011. 'Why Do Jazz Musicians Swing Their Eighth Notes?', Music Theory Spectrum, 33(1), pp. 3-36

Caswell, E. 2017. 'How the Triplet Flow Took Over Rap', Vox.com (Accessed Mar 8, 2018) https://www.vox.com/2017/9/18/16328330/migos-triplet-flow-rap

Caulfield, K. 2018. 'Cardi B's Invasion of Privacy Debuts at No. 1 on Billboard 200 Chart.' Billboard.com (Accessed Feb 7, 2019) https://www.billboard.com/articles/columns/chartbeat/8337801/cardi-b-invasion-of-privacy-debuts-at-no-1-on-billboard-200-album-chart

Condit-Schultz, N. 2016. 'MCFlow: A Digital Corpus of Rap Transcriptions', Empirical Musicology Review, 11(2), pp. 127-147

Cowell, T. W. 2015. 'Someone Tossed a Trap Beat Beneath Snoop Dogg Imitating the Migos Flow and It's Surprisingly Great', Complex.com (Accessed Mar 8, 2018) http://www.complex.com/music/2015/08/snoop-dogg-making-fun-of-migos-finally-getsthe-trap-beat-treatment

Danielsen, A. 2010. Musical Rhythm in the age of Digital Reproduction. Ashgate (Burlington VT)

De Clercq, T. 2016. 'Measuring a Measure: Absolute Time as a Factor for Determining Bar Lengths and Meter in Pop/Rock Music', Music Theory Online, 22(3)

Drake, D. 2014. 'Tracing the Lineage of the Migos Flow', Complex.com (Accessed Mar 6, 2018) http://www.complex.com/music/2014/03/tracing-the-lineage-of-the-migos-flow

Duinker, B. 2017. 'The Emancipation of Metric Displacement Dissonance in Hip-Hop Music', Paper presented at the Annual Meeting of the Society for Music Theory, Arlington VA, Nov 2-5

Duinker, B. \& D. Martin. 2017. 'In Search of the Golden Age Hip-Hop Sound (1986-1996)', Empirical Musicology Review, 12(1), pp. 80-100

DuVernay, A. 2008. This is the Life, Forward Movement (Los Angeles CA)

Friedman, A. 2016. 'Frauds in Atlanta? Why the Controversy over Desiigner's "Panda" Goes Deeper than you Think', Factmag.com (Accessed Mar 8, 2018) http:/www.factmag.com/2016/04/26/panda-desiigner-future-new-york-rap/

Gomez-Peck, S. 2019. "'Money Flow": Triplet Flow and its Antecedents in the Golden Age of Hip-Hop.' Paper presented at the Hip-Hop in the Golden Age Conference, Indiana University Bloomington, Feb. 16-17

This is an accepted manuscript. Please cite as:

Duinker, Ben. 2019. "Good Things Come in Threes: Triplet Flow in Recent Hip-Hop Music." Popular Music 38 (3): 423-456. 
GQ Music. 2016. 'Desiigner, the Rapper Who Sounds Like Future, Now Has What Future Doesn't: A No. 1 Single', GQ Magazine (Accessed Mar 8, 2018) https://www.gq.com/story/desiigner-panda-no-1

Grem, D. E. 2006. 'The South Got Something to Say': Atlanta's Dirty South and the Southernization of Hip-Hop America', Southern Cultures, 12(4), pp. 55-73

Krebs, H. 1999. Fantasy Pieces: Metrical Dissonance in the Music of Robert Schumann. Oxford University Press (New York NY) . 2014. 'Treading Robert Schumann's New Path: Understanding Declamation in the Late Lieder through Analysis and Recomposition', Music Theory Online, 20(4)

Krims, A. 2000. Rap Music and the Poetics of Identity. Cambridge University Press (Cambridge UK)

Lee, A. 2014. 'Why Rap Regionalism is Fading', Maclean's Magazine (Accessed Mar 6, 2018) http://www.macleans.ca/culture/why-rap-regionalism-is-fading

Mendizabahl, A. 2016. 'Desiigner's "Panda" Reaches No. 1 on Hot Rap Songs Chart, Soars into Top 10 on Hot 100', Billboard Magazine (Accessed Mar 8, 2018) https://www.billboard.com/articles/columns/chart-beat/7333104/desiigner-panda-hot-rapsongs-chart

Molanphy, C. 2016. 'Why is Desiigner's "Panda" No. 1?', Slate Magazine (Accessed Mar 8, 2018) http://www.slate.com/blogs/browbeat/2016/05/02/why_desiigner_s_panda_is_no_1_on_t he billboard hot 100.html

Ohriner, M. 2016. 'Metric Ambiguity and Flow in Rap Music: A Corpus-Assisted Study of Outkast's 'Mainstream' (1996)', Empirical Musicology Review, 11(2), pp. 153-179 . 2017. '(Why) Does Talib Kweli Rhyme Off-Beat?' Paper presented at the Annual Meeting of the Society for Music Theory, Arlington VA, Nov 2-5

Pellegrino, F. et al. 2011. 'A Cross-Language Perspective on Speech Information Rate', Language, 87(3), pp. 539-558

Recording Industry Association of America. Desiigner: Panda, (Accessed Mar 6, 2018) https://www.riaa.com/gold-platinum/?tab_active=defaultaward\&ar=DESIIGNER\&ti=PANDA8

Sarig, R. 2007. Third Coast: How Southern Hip-Hop Became a Thing. Da Capo Press (Cambridge, MA)

Setaro, S. 2016. 'Are the Sounds of Regional Hip-Hop Going Extinct?', Observer.com (Accessed Mar 6, 2018) http://observer.com/2016/03/are-the-sounds-of-regional-hip-hopscenes-dead/

Schmidt A. B. et al. 2016. 'Is it the Migos' flow? Tracing the use of triplet flows in Hip-Hop', Genius.com (Accessed Mar 6, 2018) https://genius.com/Queenofcoplaints-is-it-themigos-flow-tracing-the-use-of-triplet-flows-in-hip-hop-lyrics

Temperley, D. 2007. 'The Melodic-Harmonic 'Divorce' in Rock', Popular Music, 26(2), pp. 323-342

Walser, R. 1995. 'Rhythm, Rhyme, and Rhetoric in the Music of Public Enemy', Ethnomusicology, 39(2), pp. 193-217

Weiner, J. 2012. 'Where You're From and Where You're @: Azelia Banks, A\$AP Rocky, TNGHT, and the End of Hip-Hop Regionalism', Slate.com (Accessed Mar 6, 2018) http://www.slate.com/articles/arts/music_box/2012/06/azealia_banks_a_ap_rocky_tnght and_the_end_of_hip_hop_regionalism_.html 


\section{Discography}

Afrika Bambaataa \& the Soulsonic Force, 'Planet Rock'. Planet Rock: The Album. Tommy Boy / Warner Bros. 1982

Ariana Grande, 'God Is a Woman'. Sweetener. Republic. 2018

Big Sean, 'Dark Sky (Skyscrapers)'. Dark Sky Paradise. GOOD Music / Def Jam. 2015 , 'Paradise (Extended)'. Dark Sky Paradise. GOOD Music / Def Jam. 2015

_, 'Blessings'. Dark Sky Paradise. GOOD Music / Def Jam. 2015

B.O.N.E. Enterpri\$e, 'Flow Motion'. Faces of Death. Stoney Burke. 1993

Bone Thugs-n-Harmony, 'No Surrender'. Creepin on ah Come Up. Ruthless. 1994

-, 'Thuggish Ruggish Bone'. Creepin on ah Come Up. Ruthless. 1994

, '1st of tha Month'. E. 1999 Eternal. Ruthless. 1995

_, 'Tha Crossroads'. E. 1999 Eternal. Ruthless. 1995

Cardi B, 'Bodak Yellow'. Invasion of Privacy. Atlantic. 2018

Childish Gambino, 'This is America'. Non-album Single. mcDJ / RCA. 2018

Desiigner, 'Panda'. New English. GOOD Music / Def Jam. 2016

Dr. Dre, 'Nuthin' but a "G” Thang'. The Chronic. Death Row. 1992

Freestyle Fellowship, 'Six Tray'. Innercity Griots. 4th \& B'way. 1993

G-Eazy, 'Me Myself \& I'. When It's Dark Out. RCA. 2015

The Get Down Brothers, 'Get Down Brothers vs. Notorious 3'. The Get Down (soundtrack). RCA. 2016

Jay Z, 'My First Song'. The Black Album. Rock-A-Fella / Def Jam. 2003

Jaz-O, 'The Originators'. To Your Soul. EMI. 1990

Kanye West, 'Black Skinhead'. Yeezus. Def Jam. 2013

Kendrick Lamar, 'Backstreet Freestyle'. Good Kid, M.A.D.D. City. Top Dawg / Aftermath. 2012 , 'Swimming Pools'. Good Kid, M.A.D.D. City. Top Dawg / Aftermath. 2012

Lil' Donald, 'Fuck Panda'. Still Here. Kuhnsinity. 2017

Lil' Jon \& the East Side Boyz, 'Who U Wit'. Get Crunk Who U Wit: Da Album. Mirror Image. 1997

—, 'Get Low'. Kings of Crunk. BME / TVT. 2002

Madvillain, 'All Caps'. Madvillainy. Stones Throw. 2004

Meek Mill, 'Ooh Kill 'em'. Unreleased Killadelphia Muzik. Blackmarket. 2014

Migos, 'Versace'. Y.R.N. (Young Rich Niggas). Quality Control. 2013

The Pharcyde, 'Passin' Me By'. Bizarre Ride II the Pharcyde. Delicious Vinyl. 1992

Public Enemy, 'Bring the Noise'. It Takes a Nation of Millions to Hold Us Back. Def Jam / Columbia. 1988

, 'Fight the Power'. Fear of a Black Planet. Def Jam / Columbia. 1990

Three 6 Mafia, 'Sleep'. Undergound Vol. 3: Kings of Memphis. Loud Records. 2000

_ , 'It's Hard Out Here for a Pimp'. Hustle \& Flow Soundtrack. Atlantic Grand Hustle. 2005

Roxanne Shanté, 'Roxanne's Revenge'. Non-Album Single. Pop Art. 1984

Run the Jewels, 'Oh my Darling Don't Cry'. Run the Jewels 2. Mass Appeal / RED. 2014

UTFO, 'Roxanne Roxanne'. UTFO. Select. 1985

Vince Staples, 'Senorita'. Summertime '06. ARTium / Backsmith / Def Jam. 2015

Young Thug, 'Best Friend'. Slime Season. Self-released. 2015

—, 'With That'. Barter 6. 300 Entertainment / Atlantic. 2015 